\title{
Synthesis, growth mechanism and photocatalytic activity of Zinc Oxide nanostructures: Porous microparticles versus nonporous nanoparticles
}

Ahmed Barhoum ${ }^{1,2,3^{*}}$, Johannes Melcher ${ }^{2}$, Guy Van Assche ${ }^{1 *}$ Hubert Rahier ${ }^{1}$, Mikhael Bechelany ${ }^{4}$, Manuel Fleisch ${ }^{2}$, Detlef Bahnemann ${ }^{2,5}$

${ }^{1}$ Department of Materials and Chemistry, Faculty of Engineering, Vrije Universiteit Brussel (VUB), Pleinlaan 2, 1050 Brussels, Belgium

${ }^{2}$ Institute of Technical Chemistry, Photocatalysis and Nanotechnology Research Unit, Leibniz Universität Hannover, Callinstr.3, 30167 Hannover, Germany

${ }^{3}$ Chemistry Department, Faculty of Science, Helwan University, 11795 Helwan, Cairo, Egypt

${ }^{4}$ Institut Européen des Membranes, UMR 5635 CNRS ENSCM Université Montpellier, Place Eugene Bataillon, F-34095 Montpellier cedex 5, France

${ }^{5}$ Laboratory for Nanocomposite Materials, Department of Photonics, Faculty of Physics, SaintPetersburg State University, Ulianovskaia Str.3, Peterhof, Saint-Petersburg, 198504, Russia *Email: ahmed.abdelrasoul@vub.ac.be, gvassche@vub.ac.be

\begin{abstract}
:
A simple facile method, i.e., thermal decarbonation of $\mathrm{ZnCO}_{3}$ hydroxides, was used to prepare a series of pure $\mathrm{ZnO}$ photocatalysts with controlled crystallite sizes, particle sizes and morphologies. The $\mathrm{ZnCO}_{3}$ precursor was synthesized by direct-wet carbonation in the presence of growth-control additives, i.e., organic solvents, surfactants and low molecular weight polymers. The thermal decarbonation allows for producing $\mathrm{ZnO}$ photocatalysts with sizes and shapes vary from $80 \pm 20$ $\mathrm{nm}$ nonporous rhombohedral nanoparticles to $5 \pm 0.5 \mu \mathrm{m}$ porous particles, for a constant crystallite size of $64 \pm 3 \mathrm{~nm}$. The porous $\mathrm{ZnO}$ particles $(5 \pm 0.5 \mu \mathrm{m})$ exhibits two times larger photocatalytic activity for methanol oxidation than the nonporous $\mathrm{ZnO}$ nanoparticles $(\sim 180 \pm 30 \mathrm{~nm})$. The reasons for the higher photocatalytic activity are further investigated in this work. A possible mechanism for the formation of $\mathrm{ZnCO}_{3}$ hydroxides and their transformation into porous microsized $\mathrm{ZnO}$ particles and nonporous nanoparticles are carefully discussed.
\end{abstract}


KEYWORDS: Zinc Oxide Photocatalyst, Zinc carbonate, Nonporous nanoparticles, Porous nanostructures, Direct-wet carbonation

\section{INTRODUCTION}

Considerable efforts have been devoted to design and prepare highly structured photocatalysts with various sizes and shapes with potential applications ranging from environmental remediation to energy conversion [1-5]. The variations of the photonic efficiency of photocatalyst particles are attributed to shape, size and surface area effects: the smaller the crystallites and/or particle sizes are, the higher is the photocatalytic activity $[6,7] . \mathrm{ZnO}$ is a material with a wide direct bandgap $(3.37 \mathrm{eV})$ and a high exciton binding energy $(60 \mathrm{meV})$ [8]. The morphologies of $\mathrm{ZnO}$ nanoparticles, the richest among metal oxides, can be easily controlled into desirable structures, including special structures like nanotubes [9], nanoflowers [10], nanobridges [11], nanonails [11], and nanotrees [12].

Zinc oxide powder is produced industrially by pyrometallurgical or hydrometallurgical methods. The metallurgical processes for manufacturing $\mathrm{ZnO}$ by oxidation were started in Germany in the 1700s. In 19th century, three large-scale processes, called the direct method (the American process), the indirect method (the French process), and the hydrometallurgical method were developed to produce $\mathrm{ZnO}$ pigment [13]. The direct (American) process involves vaporization and reduction of zinc ore by heating in presence of coal and then oxidation of the zinc vapor, resulting in needle-like $\mathrm{ZnO}$ particles and sometimes spheroidal [13]. In the indirect (French) process, metallic zinc is vaporized at ca. $910{ }^{\circ} \mathrm{C}$ and then the zinc vapor oxidized in air, resulting in $\mathrm{ZnO}$ particle agglomerates of sizes ranging from $100 \mathrm{~nm}$ to a few micrometres [14]. The indirect (French) process is the largest proportion for $\mathrm{ZnO}$ production, followed by the direct (American) process, and the hydrometallurgical process, which uses zinc-rich wastes [15]. More recently, several chemical methods have been developed for the production of $\mathrm{ZnO}$ sub-micron to nanoparticles, including sol-gel, hydrothermal, microemulsions, and direct precipitation, making it possible to obtain products with particles differing in shape, size, purity and desired structures [13]. The architecture of $\mathrm{ZnO}$ nanostructures with controllable dimensions, have been obtained by

adjusting the $\mathrm{Zn}^{2+}$ concentration, reaction temperature, solvent, capping agents, and quenching treatments during the reaction [16]. Unfortunately, these methods work in the laboratory and cannot always be upscaled to the industrial scale. Recently, microwave-assisted synthesis was used 
to control the growth habit of $\mathrm{ZnO}$ nanostructures [17]. This method is attractive as it allows for short reaction time, enhanced reaction selectivity, energy savings, and homogeneous volumetric heating. The microwaves can transfer the energy directly to the reacting species, sometimes termed "molecular heating", strongly influencing the nucleation and growth, and thus the shape and size of the $\mathrm{ZnO}$ particles [13], [17].

Nanostructured $\mathrm{ZnO}$, aside from $\mathrm{TiO}_{2}$, is considered to be a promising material for photocatalysis [18], disinfection and purification of air and water [19], and solar energy conversion [20], due to its lower cost, high photoactivity, and environment-friendly feature. The drawback of $\mathrm{ZnO}$ as photocatalytic material is that $\mathrm{ZnO}$ only absorbs in the UV range, while only about $5 \%$ of the solar energy is emitted in the UV range [19]. Furthermore, the aggregation of $\mathrm{ZnO}$ nanoparticles during aging and the difficulty in reclaiming the $\mathrm{ZnO}$ nanoparticles limits the practical applications [21]. Recently, efforts have been made to enhance the photocatalytic activity and selectivity of $\mathrm{ZnO}$ by tailoring the particle shape [3]. For example, the photocatalytic activity of different $\mathrm{ZnO}$ nanostructures towards resorcinol degradation follows the order: sphere-like > rod-like > flakelike shape [16]. Recent investigations showed that porous $\mathrm{ZnO}$ nanostructures show superior photocatalytic activity and selectivity comparing to nonporous $\mathrm{ZnO}$ nanoparticles. For example, porous $\mathrm{ZnO}$ nanopyramids have shown a high adsorption and degradation rate for the acidic dyes compared to the nonporous $\mathrm{ZnO}$ nanopyramids [22]. Porous nanostructures do not only maintain a high surface-to-volume ratio resulting in a strong photocatalytic activity, but also prevent extensive aggregation and facilitate the recovery of the particles compared to nano photocatalysts, especially below $50 \mathrm{~nm}$. The porous nanostructures create very nice channels that can provide: (i) superior light absorption and photocatalytic activity through light scattering effects, (ii) higher durability, dipersability and lower toxicity than the NPs, and (iii) minimum tortuosity leading to enhanced mass transport and improved light harvesting efficiency [21]'[23].

Understanding the growth and self-assembling of nanoparticles into nanostructures are crucial for a good control of the size, shape and photocatalytic activity of the photocatalysts. In the liquidphase, the growth-control additives control the nuclei-solution interfacial energy [24]. Therefore they play a critical role in the orientation of the primary nanocrystals, formed in the early stages of the reaction, into assembled nanostructures [25]'[26]: (i) Selective-adsorption effect: Growthcontrol additives could adsorb on the growing crystals, change the energy of the crystal facets, affect atom deposition rates into various crystal facets, and control crystal growth rates [27],[28]; 
(ii) Complexation effect: Growth-control additives may stabilize clusters in suspension and impede the nucleation, and this leads to fewer nuclei and formation of larger particles (e.g., induce Ostwald ripening)[29],[30]; and (iii) Surface-stabilization effect: Growth-control additives may stabilize the nanocrystal by shielding the surfaces. This shielding inhibits the dissolution of nanocrystals back into solution and results in small sized particles with narrow size distribution (e.g., reduce Ostwald ripening) [31]. Interestingly, recent investigations found that the selective adsorption of growth-control additives during synthesis of $\mathrm{ZnO}$ can alter the surface activity of $\mathrm{ZnO}$ crystals and offer intrinsic photocatalytic properties. For example, porous $\mathrm{ZnO}$ particles prepared by organic-combustion method using oxalic acid shows a higher activity toward degradation of orange $\mathrm{G}$ dye compared to $\mathrm{ZnO}$ prepared with other reagents, such as urea, citric acid, glycine, dextrose, and oxalyldihydrazide [32].

Controlling shapes and sizes of photocatalytic materials, provides a high versatility for enhancing the photocatalytic activity and selectivity compared to what can be achieved otherwise. The shape and size control of photocatalytic materials is a complex process, requiring a fundamental comprehension of the interactions of reagents. The effect of different types of the capping agents on the shape and size of $\mathrm{ZnO}$ materials prepared via thermal decarbonation of $\mathrm{ZnCO}_{3}$ has not been extensively investigated yet. In this study, we controlled the shape and size of $\mathrm{ZnO}$ particles by using a relatively new, simple growth-controlled synthesis "thermal decarbonation". The synthesis of $\mathrm{ZnO}$ nanostructure through thermal decarbonation of $\mathrm{ZnCO}_{3}$ which is solid state synthesis approach. Unlike liquid-phase synthesis, thermal decarbonation is very effective approach to produce uniform and highly dispersed ZnO NPs, without further mechanical and physical treatments, i.e., grinding and sonication. $\mathrm{ZnCO}_{3}$ hydroxides particles were prepared by direct precipitation from $\mathrm{ZnCl}_{2}$ with $\left(\mathrm{NH}_{4}\right)_{2} \mathrm{CO}_{3}$ in solution, in the presence of different growth-control additives, i.e., ethanol, glycerol, triton X-100, polyvinylpyrrolidone (PVP) and poly(acrylic acid sodium salt) (PAC). These additives were chosen because of their high bonding abilities and dispersive interactions. Porous microsized $\mathrm{ZnO}$ particles and nonporous nanoparticle (photocatalysts) were prepared through thermal decarbonation of the prepared $\mathrm{ZnCO}_{3}$ particles. The study further looks for fundamental understanding of the relationship between the growthcontrol molecules, particle shape and size, and photocatalytic activity of $\mathrm{ZnO}$ photocatalysts. 


\section{EXPERIMENTAL SECTION}

\subsection{Materials}

Chemicals were purchased with given analytical grades and used without further purification. Zinc chloride $\left(\mathrm{ZnCl}_{2},+98 \%\right.$, Sigma), ammonium carbonate $\left(\left(\mathrm{NH}_{4}\right)_{2} \mathrm{CO}_{3}\right), \geq 30.0 \% \mathrm{NH}_{3}$ basis, SigmaAldrich), ethanol $\left(\mathrm{C}_{2} \mathrm{H}_{5} \mathrm{OH}, 96 \%\right.$, Sigma), glycerol $\left(\mathrm{C}_{3} \mathrm{H}_{8} \mathrm{O}_{3}, \geq 99 \%\right.$, Sigma), polyvinylpyrrolidone (PVP, MW 10,000, Sigma), poly(acrylic acid sodium salt) (PAC, $\mathrm{M}_{\mathrm{w}} \sim 5100$ g.mol ${ }^{-1}$, Sigma), Triton X-100 (Trit, $\mathrm{M}_{\mathrm{w}} \sim 10,000$ g.mol ${ }^{-1}$, Sigma), and deionized water (18.2 M $\Omega . \mathrm{cm}^{-1}$ ) were used to prepare the targeted $\mathrm{ZnO}$ photocatalysts. The chemical structures of all investigated growthcontrol additives are shown in Figure 1.

(a)

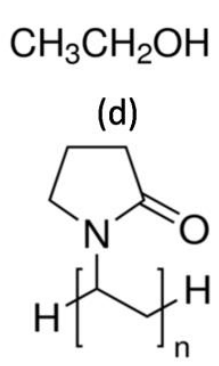

(b)<smiles>OCC(O)CO</smiles>

(e)<smiles>CCC(C(=O)O[Na])C(C)(C)C</smiles><smiles>CC(CC(C)(C)C)Oc1ccc(C(C)(C)CO[TlH])cc1</smiles>

Figure 1. Chemical structures of the utilized growth-control additives: (a) ethanol; (b) glycerol; (c) PAC; (d) PVP; and (e) Triton X-100 ( $n=9-10)$

\subsection{Preparation of $\mathrm{ZnCO}_{3}$ hydroxides and $\mathrm{ZnO}$ particles}

Porous microsized $\mathrm{ZnO}$ particles and nonporous nanoparticles with varying shapes and sizes were synthesized via thermal decarbonation of $\mathrm{ZnCO}_{3}$ hydroxides particles. The latter particles were prepared by titration of $1.5 \mathrm{M}\left(\mathrm{NH}_{4}\right)_{2} \mathrm{CO}_{3}$ solution against $400 \mathrm{~mL}$ of $0.33 \mathrm{M} \mathrm{ZnCl}_{2}$ solution, containing growth-control additives (see Table 1), at room temperature and under vigorous stirring for $30 \mathrm{~min}$. The $\mathrm{pH}$ of the pure $\mathrm{ZnCl}_{2}$ solutions was approximately 5. Once the $\mathrm{pH}$ of the solutions increased from 5 to 9, the carbonation reaction of $\mathrm{Zn}^{2+}$ ions was almost complete, the titration was stopped and then the mixture was further stirred for $20 \mathrm{~min}$. The $\mathrm{ZnCO}_{3}$ hydroxides particles were filtered and washed with deionized water and then allowed to dry at $100{ }^{\circ} \mathrm{C}$ for $24 \mathrm{~h}$ and grinded in a mortar. The $\mathrm{ZnCO}_{3}$ hydroxides particles produced were annealed at $600{ }^{\circ} \mathrm{C}$ for $24 \mathrm{~h}$ using heating and cooling rates of $1 \mathrm{~K} \mathrm{~min}^{-1}$, resulting in powder $\mathrm{ZnO}$ particles without any further mechanical treatment. The preparation conditions are listed in Table 1. 
Table 1. The experimental preparation conditions of all $\mathrm{ZnCO}_{3}$ hydroxides particles

\begin{tabular}{|c|c|c|c|c|}
\hline \multirow{2}{*}{ Samples } & \multicolumn{3}{|c|}{$\mathrm{ZnCl}_{2}$ solution } & \multirow{2}{*}{$\begin{array}{c}\left.\mathbf{( N H}_{4}\right)_{2} \mathbf{C O}_{3} \\
\text { solution }\end{array}$} \\
\cline { 2 - 4 } & $\mathbf{Z n C l}_{2(\mathbf{s})}$ & $\mathbf{H}_{2} \mathbf{O}_{(\mathrm{I})}$ & Growth-control additives & $1.5 \mathrm{M}$ \\
\hline ZC-Eth & $18 \mathrm{~g}$ & $350 \mathrm{~mL}$ & $50 \mathrm{~mL}$ ethanol & $1.5 \mathrm{M}$ \\
\hline ZC-Gly & $18 \mathrm{~g}$ & $350 \mathrm{~mL}$ & $50 \mathrm{~mL}$ glycerol & $1.5 \mathrm{M}$ \\
\hline ZC-PVP & $18 \mathrm{~g}$ & $400 \mathrm{~mL}$ & $1 \mathrm{~g}$ polyvinylpyrrolidone & $1.5 \mathrm{M}$ \\
\hline ZC-PAC & $18 \mathrm{~g}$ & $400 \mathrm{~mL}$ & $1 \mathrm{~g}$ poly(acrylic acid sodium salt) & $1.5 \mathrm{M}$ \\
\hline ZC-Trit & $18 \mathrm{~g}$ & $400 \mathrm{~mL}$ & $1 \mathrm{~g}$ Triton X-100 & \\
\hline
\end{tabular}

\subsection{Characterization of $\mathrm{ZnCO}_{3}$ hydroxides and $\mathrm{ZnO}$ particles}

Phase identification of all samples was performed using an X-ray diffractometer (PANalyticalXpert- PRO diffractometer equipped with an accelerator detector using Ni-filtered $\mathrm{Cu}$-radiation) with $\mathrm{Cu} \mathrm{K} \alpha$ radiation $(\lambda=0.15406 \mathrm{~nm})$ at $40 \mathrm{kV}$ and $20 \mathrm{~mA}$. The scanning step size was $0.0167113^{\circ}$. The crystallite size of $\mathrm{ZnO}$ particles was determined from the $\mathrm{X}$-ray diffraction data using the Debye-Scherrer formula [33]:

$$
d=\frac{K \lambda}{\beta \cos \theta}
$$

where $d$ is the crystallite size, $\mathrm{K}$ is a dimensionless shape factor, with a value close to unity. The shape factor has a typical value of about 0.9 , but varies with the actual shape of the crystallite, $\beta$ is the full width at half maximum (FWHM) of the most intense diffraction peak, $\lambda$ is the wavelength of $\mathrm{Cu}$ target, and $\theta$ is the Bragg angle. Thermogravimetric analysis (TA Instruments, TGA Q5000, USA) was used to determine the thermal transitions of the synthesized $\mathrm{ZnCO}_{3}$ particles. The samples were heated at $10 \mathrm{~K} \mathrm{~min}^{-1}$ from 60 to $1000^{\circ} \mathrm{C}$ in an air atmosphere. $\mathrm{ZnO}$ content in the prepared $\mathrm{ZnCO}_{3}$ particles was calculated from the weight change curve of the TGA curve at 600 ${ }^{\circ} \mathrm{C}$, after complete decomposition of the $\mathrm{ZnCO}_{3}$ particles and liberation of $\mathrm{CO}_{2}$ and $\mathrm{H}_{2} \mathrm{O}$ molecules. The nanostructure investigation of the $\mathrm{ZnCO}_{3}$ particles was carried out by scanning electron microscopy (SEM, Hitachi S4800, Japan). Particle size distribution analysis is based on more than 50 particles. The $\mathrm{ZnO}$ particles were characterized by using field emission scanning electron microscope (FESEM, JEOL JSM-6700F, Japan). The specific surface area was calculated from the adsorption isotherm of nitrogen (BET; model Nova 1200, Yuasa Ionics, Osaka, Japan). 


\subsection{Bandgap determination test of the $\mathrm{ZnO}$ particles}

$\mathrm{UV}-\mathrm{Vis}$ reflectance data were recorded to determine the bandgap of the prepared $\mathrm{ZnO}$ photocatalysts. The UV-Vis reflectance data measured in this work were converted to the absorption coefficient $F(R)$ values according to the Kubelka-Munk equation [34]:

$$
F(R)=\frac{(1-R)^{2}}{2 R}
$$

where $R$ is the proportion of reflected light. Plots of this parameter were used to determine the bandgap energy by extrapolating the linear portion of the absorption transition using a leastsquares regression to zero, giving the corresponding photon energy. The bandgap of the photocatalyst was identified by diffuse reflectance spectroscopy (DRS) at the wavelength range of 200-800 nm using a Varian Cary 100 Scan UV-Vis system equipped with a Lab sphere integrating sphere diffuse reflectance accessory using $\mathrm{BaSO}_{4}$ as a reference material. The prepared powder was uniformly pressed in the sample holder that was placed in the integrating sphere for the reflectance measurements.

\subsection{Photocatalytic activity tests of the $\mathrm{ZnO}$ particles}

The photocatalytic oxidation of methanol was carried out in a continuously stirred open top boron silica glass reactor $(\varnothing=4.15 \mathrm{~cm})$. The reactor was filled with $30 \mathrm{~mL}$ aqueous solution of methanol at a concentration of $30 \mathrm{mM}$ and a $\mathrm{ZnO}$ catalyst concentration of $1 \mathrm{~g} \cdot \mathrm{L}^{-1}$ and then closed to avoid potential evaporation of methanol. Before the UV irradiation was started, the prepared suspensions were stored in the dark for at least $3 \mathrm{~h}$ to reach adsorption equilibrium. Next, UV irradiation was performed by a UV-lamp (Philips 40W CLEO Performance, Germany) using light intensities of $\sim 9.3 \mathrm{~W} \cdot \mathrm{m}^{-2}$, which were measured for each sample separately using a $365 \mathrm{~nm} \mathrm{UV-A}$ light meter (Lutron Electronic Enterprise UVA-365, Taiwan). Samples were taken at regular intervals (0, 10, 20 and $30 \mathrm{~min}$ ) from the reactor with the catalyst being removed from the liquid phase by centrifuging (Eppendorf Centrifuge 5415 R, USA). The photooxidation rate was determined by measuring the formaldehyde $(\mathrm{HCHO})$ concentration generated as a result of methanol oxidation during the illumination according to the Nash method. Therefore an aqueous mixture of ammonium acetate, acetyl acetone and acetic acid was prepared according to the original procedure [35]. Because Nash's Reagent is light sensitive and was kept in dark-glass reagent bottle at all time. The produced formaldehyde molecules react with the Nash Reagent to form yellow 
colored 3,5-diacetyl-1,4-dihydrolutidine, with a maximum absorbance at $412 \mathrm{~nm}$ and a known absorption coefficient of 586,444 $\mathrm{L} \mathrm{mol}^{-1} \mathrm{~m}^{-1}$. We found that the reaction can be assumed to follow zero-order kinetics until a HCHO concentration of $3.5 \times 10^{-4} \mathrm{~mol} \mathrm{~L}^{-1}$ was attained. The relative error of the measured $\mathrm{HCHO}$ concentration was $\pm 4 \%$ as judged from repetition experiments. The UV-absorbance measurements were performed using a Varian Cary100 Scan UV-Vis spectrophotometer, after an incubation time of $15 \mathrm{~min}$ at $60{ }^{\circ} \mathrm{C}$. The photonic efficiency was calculated for each experiment as the ratio of the photocatalytic oxidation rate and the incident light intensity, as given in the following equation [36]:

$$
\xi=\frac{r \times 100}{I}
$$

Where $\xi$ is the photonic efficiency $(\%), r$ is the photooxidation rate of methanol $\left(\mathrm{mol} \cdot \mathrm{s}^{-1}\right)$, and $I$ the illumination area multiplied by the incident photon flux $\left(3.84 \times 10^{-8} \mathrm{~mol} \cdot \mathrm{s}^{-1}\right)$. The photooxidation rate was determined by plotting the concentration of methanol against illumination time. All the values given in the present work are based on three measurements at least.

\section{RESULTS AND DISCUSSION}

The growth-controlled, in situ synthesis of $\mathrm{ZnCO}_{3}$ particles was carried out with the growthcontrol additives shown in Figure 1. The polymorphs, crystallite sizes, particle shapes and sizes, specific-surface areas, onset temperatures of thermal decomposition, bandgaps and photonic efficiencies of the prepared $\mathrm{ZnCO}_{3}$ and $\mathrm{ZnO}$ particles are summarized in Tables 2 and 3, respectively. The selected additives do not only affect the growth and assembly of $\mathrm{ZnCO}_{3}$ hydroxides particles, but also the thermal transformation of these particles into $\mathrm{ZnO}$ nanostructures.

Table 2. Characteristics of the as-prepared $\mathrm{ZnCO}_{3}$ structures

\begin{tabular}{|c|c|c|c|c|c|c|}
\hline $\begin{array}{c}\mathrm{ZnCO}_{3} \\
\text { Samples }\end{array}$ & $\begin{array}{l}\text { Crystal } \\
\text { structure }\end{array}$ & $\begin{array}{l}\text { Crystallite } \\
\text { size } \\
(\mathrm{nm})\end{array}$ & $\begin{array}{c}\text { Particle } \\
\text { Size } \\
(\mu \mathrm{m})\end{array}$ & $\begin{array}{l}\text { Particle } \\
\text { Shape }\end{array}$ & $\begin{array}{c}\text { Onset } \\
\text { Decom. } \\
\text { Temp. } \\
\left({ }^{\circ} \mathrm{C}\right)\end{array}$ & $\begin{array}{c}\text { Zno } \\
\text { content } \\
(w t \%)\end{array}$ \\
\hline $\mathrm{ZC}-\mathrm{H}_{2} \mathrm{O}$ & $\begin{array}{l}\text { Hydrozincite: } \\
\mathrm{Zn}_{5}\left(\mathrm{CO}_{3}\right)_{2}(\mathrm{OH})_{6}\end{array}$ & 60 & $0.5-1.0$ & nanosheets & $230 \pm 5$ & $68.4 \pm 0.4$ \\
\hline ZC-Eth & $\begin{array}{l}\text { Hydrozincite: } \\
\mathrm{Zn}_{5}\left(\mathrm{CO}_{3}\right)_{2}(\mathrm{OH})_{6}\end{array}$ & 60 & $0.4-0.6$ & nanosheets & $219 \pm 5$ & $67.3 \pm 0.4$ \\
\hline ZC-Gly & $\begin{array}{c}\text { Hydrozincite: } \\
\mathrm{Zn}_{5}\left(\mathrm{CO}_{3}\right)_{2}(\mathrm{OH})_{6}\end{array}$ & 30 & $0.5-1.0$ & $\begin{array}{l}\text { rod-like } \\
\text { particles }\end{array}$ & $196 \pm 5$ & $66.1 \pm 0.2$ \\
\hline
\end{tabular}




\begin{tabular}{|c|c|c|c|c|c|c|}
\hline ZC-PAC & $\begin{array}{c}\text { Hydrozincite: } \\
\mathrm{Zn} 5\left(\mathrm{CO}_{3}\right)_{2}(\mathrm{OH})_{6}\end{array}$ & 31 & $0.5-2.0$ & $\begin{array}{c}\text { Stacks of } \\
\text { Nanosheets }\end{array}$ & $222 \pm 2$ & $72.2 \pm 0.3$ \\
\hline ZC-PVP & $\begin{array}{c}\text { Hydrozincite: } \\
\mathrm{Zn} 5\left(\mathrm{CO}_{3}\right)_{2}(\mathrm{OH})_{6}\end{array}$ & 30 & $0.5-4.0$ & $\begin{array}{c}\text { pyramidal-shape of } \\
\text { nanosheets }\end{array}$ & $236 \pm 1$ & $72.1 \pm 0.5$ \\
\hline ZC-Trit & $\begin{array}{c}\text { Hydrozincite: } \\
\mathrm{Zn}\left(\mathrm{CO}_{3}\right)_{2}(\mathrm{OH})_{6}\end{array}$ & 31 & $4.0-8.0$ & $\begin{array}{c}\text { pyramidal-shape of } \\
\text { nanosheets }\end{array}$ & $238 \pm 1$ & $72.4 \pm 0.4$ \\
\hline
\end{tabular}

Table 3. Characteristics of the prepared $\mathrm{ZnO}$ photocatalysts

\begin{tabular}{|c|c|c|c|c|c|c|c|}
\hline $\begin{array}{c}\text { ZnO } \\
\text { Photo- } \\
\text { catalysts }\end{array}$ & $\begin{array}{c}\text { Crystal } \\
\text { structure }\end{array}$ & $\begin{array}{c}\text { Crystallite } \\
\mathbf{s i z e} \\
(\mathbf{n m})\end{array}$ & $\begin{array}{c}\text { Particle } \\
\text { Diameter }(\mathbf{n m})\end{array}$ & $\begin{array}{c}\text { Particle } \\
\text { Morphology }\end{array}$ & $\begin{array}{c}\text { Surface } \\
\text { area } \\
\left(\mathbf{m}^{\mathbf{2}} \cdot \mathbf{g}^{-\mathbf{1}} \mathbf{)}\right.\end{array}$ & $\begin{array}{c}\text { Bandgap } \\
\mathbf{( \mathbf { e V } )}\end{array}$ & $\begin{array}{c}\text { Photonic } \\
\text { efficiency } \\
(\mathbf{\%})\end{array}$ \\
\hline Z-Eth & $\begin{array}{c}\text { Hexagonal } \\
\text { wurtzite }\end{array}$ & 61 & $180 \pm 30$ & Rhombohedral & $2.5 \pm 0.2$ & $\approx 3.2$ & $3.5 \pm 0.9$ \\
\hline Z-Gly & $\begin{array}{c}\text { Hexagonal } \\
\text { wurtzite }\end{array}$ & 62 & $325 \pm 125$ & Rhombohedral & $2.4 \pm 0.2$ & $\approx 3.2$ & $5.6 \pm 1.7$ \\
\hline Z-PAC & $\begin{array}{c}\text { Hexagonal } \\
\text { wurtzite }\end{array}$ & 62 & $220 \pm 90$ & Javelins & $2.9 \pm 0.1$ & $\approx 3.2$ & $6.3 \pm 1.7$ \\
\hline Z-PVP & $\begin{array}{c}\text { Hexagonal } \\
\text { wurtzite }\end{array}$ & 67 & $80 \pm 20$ & Rhombohedral & $6.0 \pm 0.2$ & $\approx 3.2$ & $6.5 \pm 1.6$ \\
\hline Z-Trit & $\begin{array}{c}\text { Hexagonal } \\
\text { wurtzite }\end{array}$ & 67 & $5000 \pm 500$ & $\begin{array}{c}\text { Porous } \\
\text { nanostructure }\end{array}$ & $7.1 \pm 0.2$ & $\approx 3.2$ & $7.5 \pm 1.6$ \\
\hline
\end{tabular}

\subsection{Crystallographic structure and phase transition}

The XRD patterns of the $\mathrm{ZnCO}_{3}$ particles synthesized in the presence of PAC (Figure 2a) are indexed to zinc carbonate hydroxide $\left(\mathrm{Zn}_{5}\left(\mathrm{CO}_{3}\right)_{2}(\mathrm{OH})_{6}\right)$, also known as hydrozincite (JCPDS00019-1458). For $\mathrm{ZC}$-Eth structures, $\mathrm{ZnCO}_{3}, \mathrm{Zn}(\mathrm{OH})_{2}$, and $\mathrm{ZnO}$ are also present. In ZC-PVP and ZC-Trit structures, these seem to be present in much smaller amounts. Furthermore, the crystallite size of the $\mathrm{ZC}-\mathrm{H}_{2} \mathrm{O}$ and ZC-Eth sample is two times larger than for the ZC-PAC, ZC-PVP, ZCGly and ZC-Trit samples (Table 2). These results indicate that polyfunctional molecules (Glycerol, PAC, PVP and Triton X-100) are more able to strongly bound and effectively inhibit the growth of primary $\mathrm{ZnCO}_{3}$ crystals than ethanol (monofunctional molecule) and water (solvent).

Interestingly, $\mathrm{ZnCO}_{3}$ hydroxides are naturally occurring as hydrozincite and it is the most common precursor of $\mathrm{ZnO}$ [37]. The $\mathrm{XRD}$ patterns of the prepared $\mathrm{ZnO}$ particles (Figure 2b) show peaks at $2 \theta=31.74^{\circ}, 34.42^{\circ}, 36.22^{\circ}, 47.53^{\circ}, 56.61^{\circ}, 62.86^{\circ}, 68.03^{\circ}$, and $69.08^{\circ}$ respectively corresponding to (100), (002), (101), (102), (110), (103), (112) and (201) of a hexagonal wurtzite structure of $\mathrm{ZnO}$ (JCPDS 79-2205). Overall, the different growth-control additives result in the same crystal structure of the prepared $\mathrm{ZnO}$ particles, slightly affecting the crystallite size. 

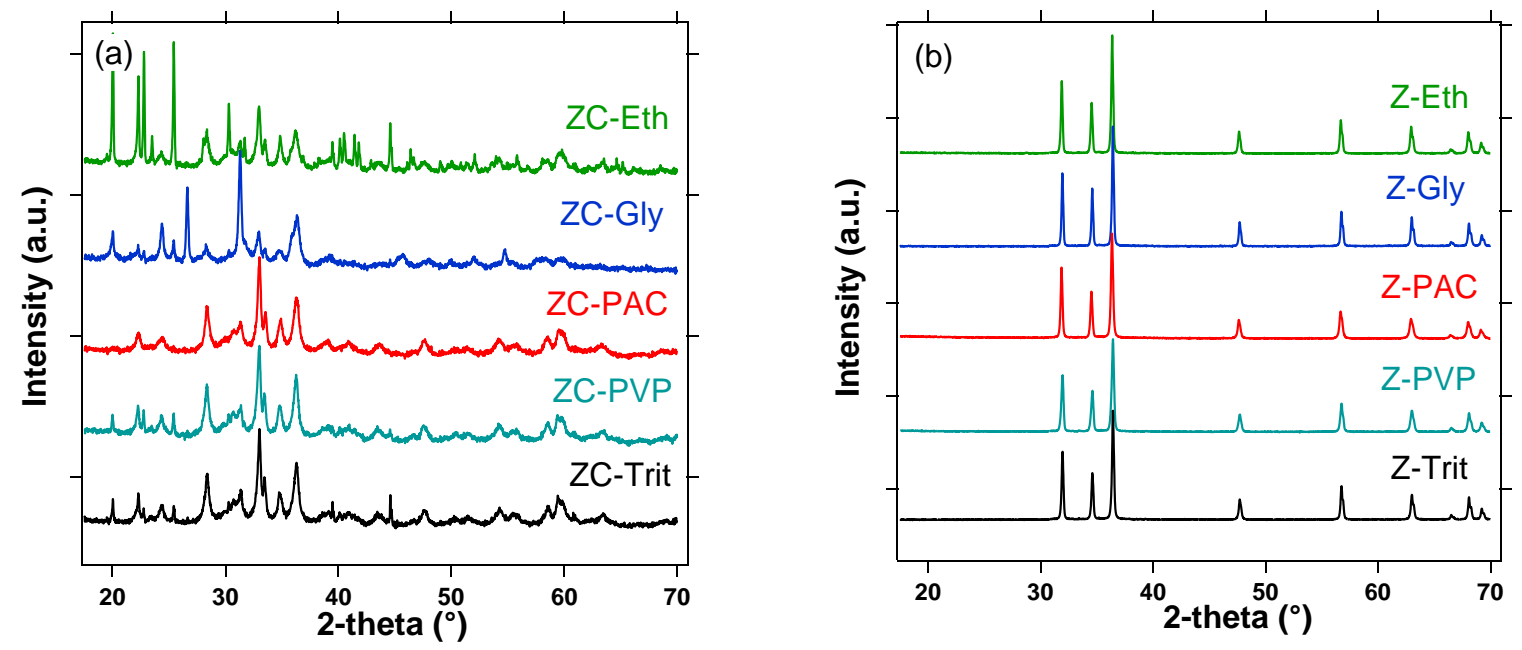

Figure 2. XRD patterns of the as-prepared particles: (a) $\mathrm{ZnCO}_{3}$ particles and (b) $\mathrm{ZnO}$ particles

\subsection{Thermal decomposition process}

Thermal decarbonation is a crucial step for the preparation of $\mathrm{ZnO}$ from $\mathrm{ZnCO}_{3}$ hydroxides. Theoretically, the thermal decarbonation of $\mathrm{Zn}_{5}\left(\mathrm{CO}_{3}\right)_{2}(\mathrm{OH})_{6}$ forming $\mathrm{ZnO}$ follows the reaction $\mathrm{Zn}_{5}\left(\mathrm{CO}_{3}\right)_{2}(\mathrm{OH})_{6} \rightarrow 5 \mathrm{ZnO}+2 \mathrm{CO}_{2}+3 \mathrm{H}_{2} \mathrm{O}$ with a theoretical mass loss of about $25.9 \mathrm{wt} \%$. The TGA curves in Figure 3 show that thermal decarbonation of the prepared $\mathrm{ZnCO}_{3}$ particles occurs in two steps: (i) the first step in the range from 60 to $150{ }^{\circ} \mathrm{C}(2.5 \mathrm{wt} \%)$ is attributed to the dehydration of surface-adsorbed water and volatile solvents and (ii) the second step from 170 to $350{ }^{\circ} \mathrm{C}(24-29 \mathrm{wt} \%)$ is due to the loss of chemically bound $\mathrm{H}_{2} \mathrm{O}$ and $\mathrm{CO}_{2}$, and the decomposition of the remaining additives. The variation in the second step ( $5 \mathrm{wt} \%)$ could be due to different amounts of additives adsorbed into/on the $\mathrm{ZnCO}_{3}$ particles or different hydration states of the $\mathrm{ZnCO}_{3}$. ZC-PVP and ZC-Trit particles show the highest onset temperatures for thermal decomposition (Table 2), the highest thermal stability, and upon thermal decomposition these samples are forming $\mathrm{ZnO}$ particles with the largest crystallite sizes obtained in this work (Table $3)$.

The production of $\mathrm{ZnO}$ from $\mathrm{ZnCO}_{3}$ hydroxides is energetically preferred due to the low decomposition temperature of $\mathrm{ZnCO}_{3}$ hydroxides, comparing with other $\mathrm{ZnO}$ precursors such as oxalates, carbonates, acetates, etc [37]. In this point of view, the prepared $\mathrm{ZnCO}_{3}$ hydroxides have great potential as flame retardant additives for polymeric materials such as polyvinyl chloride; by an integration of $\mathrm{H}_{2} \mathrm{O}$ and $\mathrm{CO}_{2}$ released during decomposition [38]. 

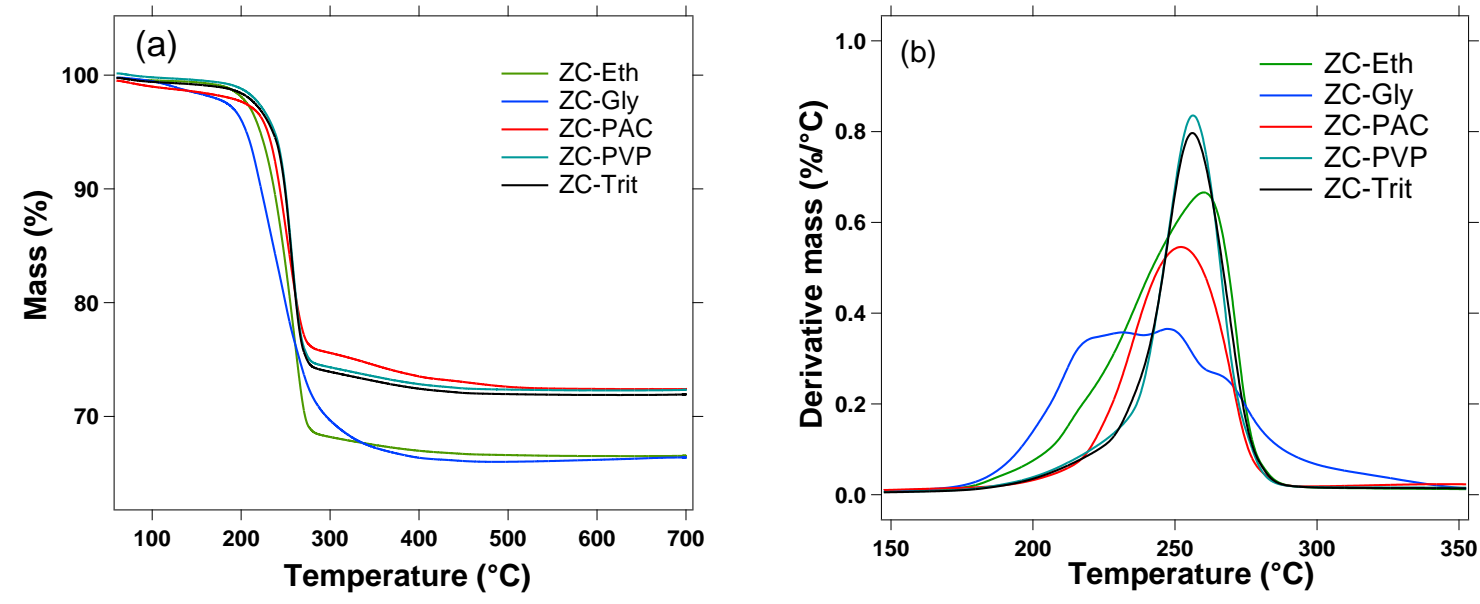

Figure 3. TGA curves of the prepared $\mathrm{ZnCO}_{3}$ particles: (a) mass versus temperature; and (b) derivative mass loss curves

\subsection{Morphological analysis}

SEM images of the $\mathrm{ZnCO}_{3}$ samples synthesized using various growth-control molecules are shown in Figure 4. ZC-Eth and ZC-Gly are aggregates of rhombohedral NPs while ZC-PVP and ZC-Trit are aggregates of sheet-like NPs. Particles of ZC-PAC (Figure 4) are composed of stacks of nanosheets, having a more homogeneous size distribution compared to the other samples. Overall, particles of ZC-Eth, ZC-PVP and ZC-Trit seem to be the most porous. The shape, size and selfassembling of the $\mathrm{ZnCO}_{3}$ particles varies owing to the different interferences of the growth-control molecules with the crystal growth process.

Thermal decarbonation of the $\mathrm{ZnCO}_{3}$ particles results in $\mathrm{ZnO}$ particles exhibiting different sizes, shapes, and porous structure, as seen by SEM analysis (Figure 5). Particles of Z-Eth, Z-Gly, Z$\mathrm{PAC}$, and Z-PVP particles are nonporous, with an average particle size ranging from 80 to $325 \mathrm{~nm}$ and particle shapes varying from rhombohedral to javelins (Table 3). The particle size increases in the order of Z-PVP $<$ Z-Eth $<$ Z-PAC $<$ Z-Gly. The particles of Z-Trit show a porous ZnO nanostructure with an average particle size about $5 \pm 0.5 \mu \mathrm{m}$ and pore sizes smaller than $50 \mathrm{~nm}$. At higher magnification, the Z-Trit particles show to be composed of nanosheets that have an etchedout appearance (Figure 5,6), increasing their specific surface area. Nitrogen adsorption and desorption isotherm studies (Table 3 ) show that the prepared porous Z-Trit particles have a larger surface area $\left(7 \mathrm{~m}^{2} \cdot \mathrm{g}^{-1}\right)$ than nonporous particles $\left(2.5-6 \mathrm{~m}^{2} \cdot \mathrm{g}^{-1}\right)$. 

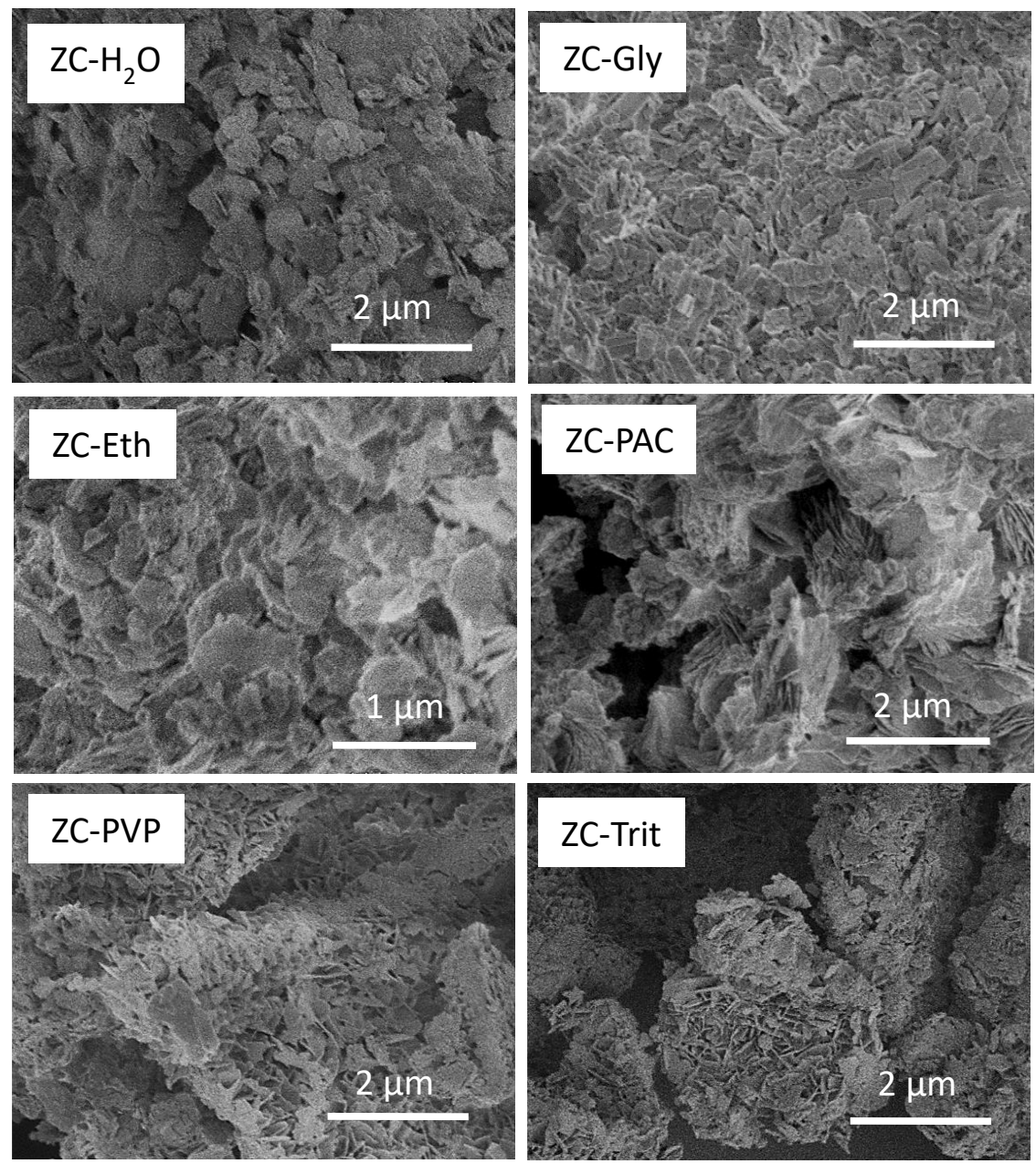

Figure 4: SEM images of the as-prepared $\mathrm{ZnCO}_{3}$ particles, prepared via direct-wet carbonation at room temperature: Z-H $2 \mathrm{O}$, Z-Eth, Z-Gly, Z-PAC, Z-PVP, and Z-Trit. 

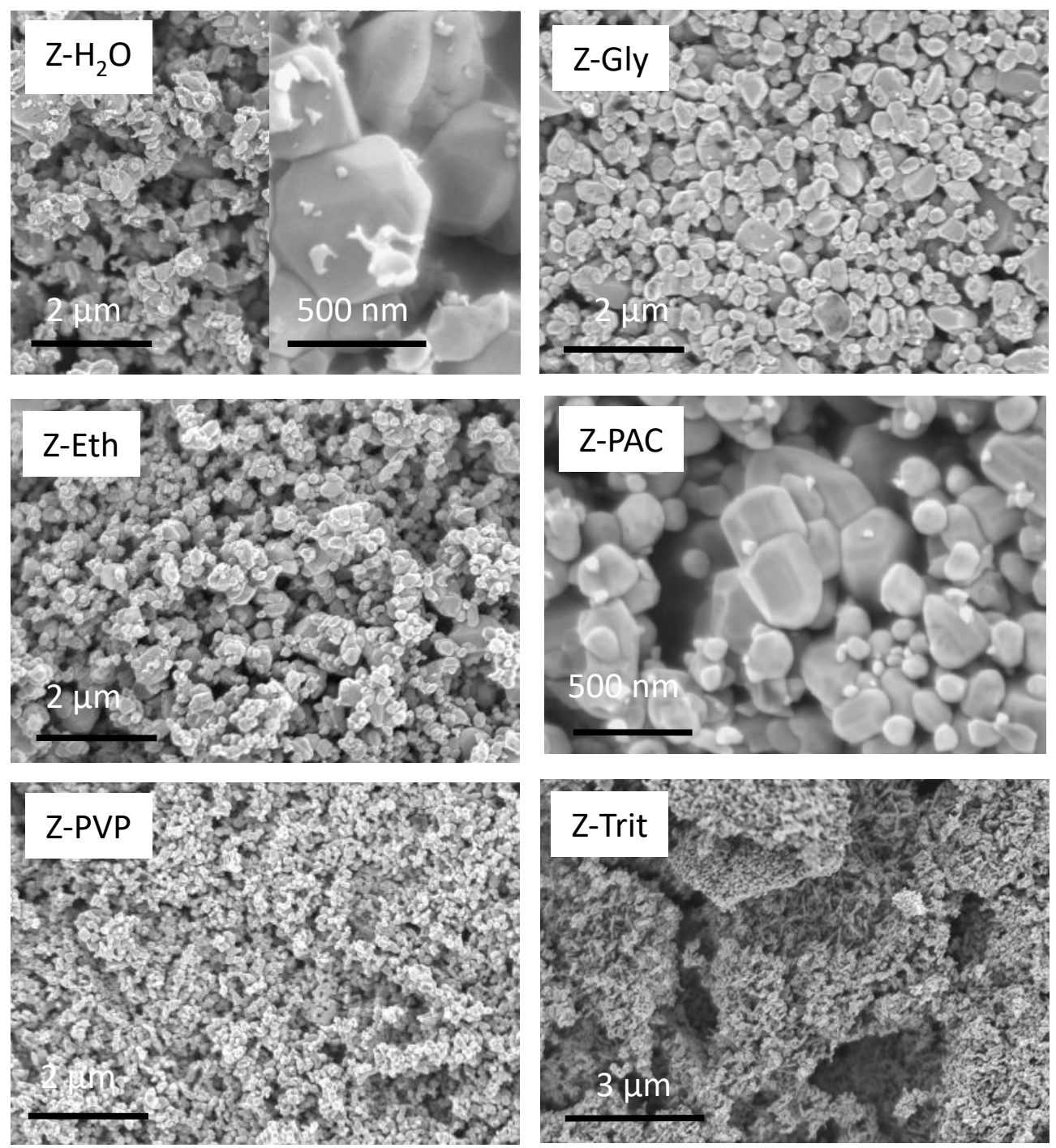

Figure 5: FESEM images of the $\mathrm{ZnO}$ particles obtained from decarbonation of the as-prepared $\mathrm{ZnCO}_{3}$ hydroxides at $600^{\circ} \mathrm{C}$ for $24 \mathrm{~h}$ : Z-H $\mathrm{H}_{2} \mathrm{O}$, Z-Eth, ZC-Gly, Z-PAC, Z-PVP, and Z-Trit. 

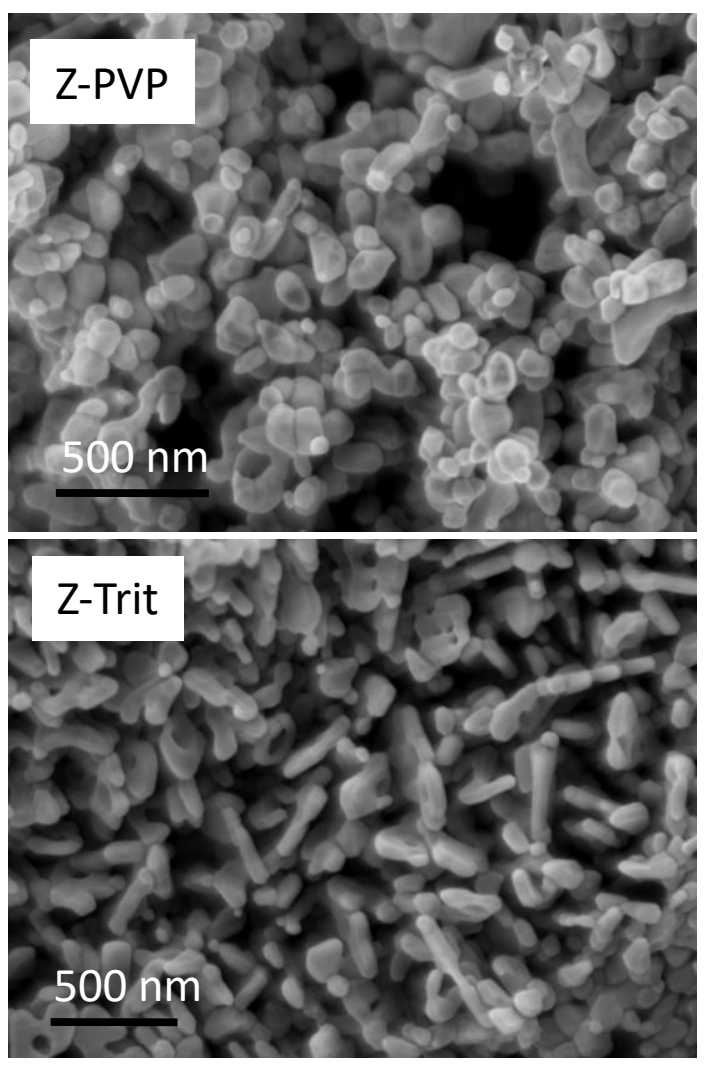

Figure 6: High magnification FESEM images showing the morphological information of as-prepared $\mathrm{ZnO}$ particles (Z-PVP and Z-Trit).

\subsection{Formation mechanism of $\mathrm{ZnCO}_{3}$ hydroxide nanostructures}

In this section, we survey the up-to-date results on the role of growth control additives on carbonate-based materials [39],[40],[41],[42]. On the basis of our observations and earlier work, it is proposed that the formation of architectured $\mathrm{Zn}_{5}\left(\mathrm{CO}_{3}\right)_{2} \cdot(\mathrm{OH})_{6}$ nanostructures involves:

(i) Hydrolysis and complexation of $\mathrm{Zn}^{2+}$ ions with increasing $\mathrm{pH}$ from 5 to $9 . \mathrm{ZnCl}_{2}$ exists in aqueous solution as $\mathrm{Zn}^{2+}, \mathrm{Zn}(\mathrm{OH})_{2}, \mathrm{Zn}(\mathrm{OH})_{3}{ }^{-}$and $\mathrm{Zn}(\mathrm{OH})_{4}{ }^{2-}$ and their concentration ratios change with increasing the $\mathrm{pH}$ of the reaction medium. Generally, $\mathrm{Zn}^{2+}$ ions hydroxylate in the presence of $\mathrm{OH}^{-}$ions forming a white precipitate $\left(\mathrm{Zn}^{2+}+2 \mathrm{OH}^{-} \rightarrow \mathrm{Zn}(\mathrm{OH})_{2}\right)$. If the concentration of $\mathrm{OH}^{-}$exceeds a certain limit, $\mathrm{Zn}(\mathrm{OH})_{2}$ will dissolve forming water-soluble zincate ion $\left(\mathrm{Zn}(\mathrm{OH})_{2}+2 \mathrm{OH}^{-} \rightarrow \mathrm{Zn}(\mathrm{OH})_{4}{ }^{2-}\right)$. Other complexes such as $\left[\mathrm{Zn}(\mathrm{OH})\left(\mathrm{H}_{2} \mathrm{O}\right)_{\mathrm{x}}\right]^{+}$and $\left[\mathrm{Zn}_{2}(\mathrm{OH})\left(\mathrm{H}_{2} \mathrm{O}\right)_{x}\right]^{3+}$ can also be formed. Other reactions can also be taken in consideration, $\mathrm{Zn}(\mathrm{OH})_{2}$ might dissolve in the presence of $\mathrm{NH}_{4}{ }^{+}$ions forming a colorless, water-soluble, zinc- 
amine complex [43]. The reaction between these species and $\mathrm{CO}_{3}{ }^{2-}$ can result in various zinc compounds such as $\mathrm{ZnCO}_{3}, \mathrm{ZnCO}_{3}$ hydroxides or other complexes [37].

(ii) Aggregation of $\mathrm{Zn}(\mathrm{OH})_{2}, \mathrm{Zn}^{2+}$, and/or $\mathrm{Zn}(\mathrm{OH})_{\mathrm{x}}{ }^{\mathrm{y}-}$ with $\mathrm{CO}_{3}{ }^{2-}$ ions forming metastable intermediate "clusters" of about $2 \mathrm{~nm}$ in diameter [44]. According to Gosner et al. clustering might occur via ions aggregation and as a result forms an amorphous phase [45].

(iii) Homogenous nucleation through aggregation of suspended amorphous clusters and partial dehydration of the aggregated amorphous phase, or heterogeneous nucleation via reaction of the $\mathrm{CO}_{3}{ }^{2-}$ ions with the partially soluble $\mathrm{Zn}(\mathrm{OH})_{2}$ precipitate, where $\mathrm{Zn}(\mathrm{OH})_{2}$ particles act as seeds for the nucleation of $\mathrm{ZnCO}_{3}$ hydroxides growth units. The amorphous clusters aggregate into the spherical morphology minimizing their total surface energy.

(iv) Particle growth and crystallization by aggregation of suspended amorphous clusters (nonclassical way) followed by partial dehydration of the amorphous phase till a critical composition (size) is reached [46].

(v) Crystallization and phase transformation of amorphous intermediates "aggregated clusters" to more ordered structure "crystal nuclei" [47]. In this step, the $\mathrm{OH}^{-}$ions preferentially bind to $\mathrm{ZnCO}_{3}$ and facilitate their growth into hexagonal crystal structure, forming primary particles of $\mathrm{Zn}_{5}\left(\mathrm{CO}_{3}\right)_{2} \cdot(\mathrm{OH})_{6}$ [37]'[48].

(vi) Oriented attachment and fusion of primary $\mathrm{ZnCO}_{3}$ particles into nanosheets [49], [50]. Oriented attachment provides an energetically favored pathway for producing defect-free crystals by the crystallographic fusion of adjacent nanoparticles [45],[51]. The primary formed particles are very small and highly energetic therefore these particles rotate continuously until they find an aligned crystallographic orientation, and then irreversibly attach on another particle by lateral atom-by-atom addition at the interface, resulting in anisotropic crystal growth [52].

(vii) Oriented attachment of primary nanosheets of $\mathrm{ZnCO}_{3}$ hydroxides into 3D structures. The surfaces of primary $\mathrm{Zn}_{5}\left(\mathrm{CO}_{3}\right)_{2} \cdot(\mathrm{OH})_{6}$ nanosheets formed during the initial growth stage have grain boundaries, which contain more defects than other regions. These boundary regions tend to reduce their surface energy through surface reconstruction, which would provide active sites for secondary heterogeneous nucleation and growth [53]. Thus, the secondary nanoparticles and/or nanosheets would grow out continuously from these active sites on the surface of the primary nanosheets. 
(viii) The orientation and growth habit of $\mathrm{ZnCO}_{3}$ hydroxide crystals are not only determined by its intrinsic structure, but also affected by the reaction conditions, such as concentration of $\mathrm{Zn}^{2+}$ and $\mathrm{CO}_{3}{ }^{2-}$ ions, temperature, $\mathrm{pH}$ of the solution and the additives. For example, growthcontrol additives bind to the primary particles that were formed at the early stage of reaction. As results they affect the secondary nucleation, i.e. growth rate and direction, forming different $\mathrm{ZnCO}_{3}$ structures [54].

Organic solvents and charged polymeric additives can exert multiple influences on crystallization in solution, such as delaying the onset of nucleation [45]. Ethanol $(\mathrm{pKa}=16)$ and glycerol $(\mathrm{pKa}=14)$ are both small, water-mixable molecules, nonionic in the $\mathrm{pH}$ range of interest ( $\mathrm{pH}=5-9)$ [55]. Ethanol (monofunctional molecule) does not induce the oriented attachment of the primary particles into 2D nanosheets. Ethanol molecules significantly inhibit the growth of primary particles and nanosheets. The size of the nanosheets formed in presence of ethanol (ZCEth) is proximally half of these prepared in pure water $\left(\mathrm{ZC}-\mathrm{H}_{2} \mathrm{O}\right)$. The different steps from cluster formation to $2 \mathrm{D}$ orientation attachment into hexagonal nanosheets, in pure $\mathrm{H}_{2} \mathrm{O}$ or ethanol/ $\mathrm{H}_{2} \mathrm{O}$ $(1 / 4 \mathrm{v} / \mathrm{v})$, are shown in Figure 7. Unlike Ethanol, glycerol (multifunctional molecule) may act as cross-linker forming chain-like complexes with $\mathrm{Zn}^{2+}$ and $\mathrm{CO}_{3}{ }^{2-}$ ions and direct the building blocks into rod-like morphology, (see Figure 8).

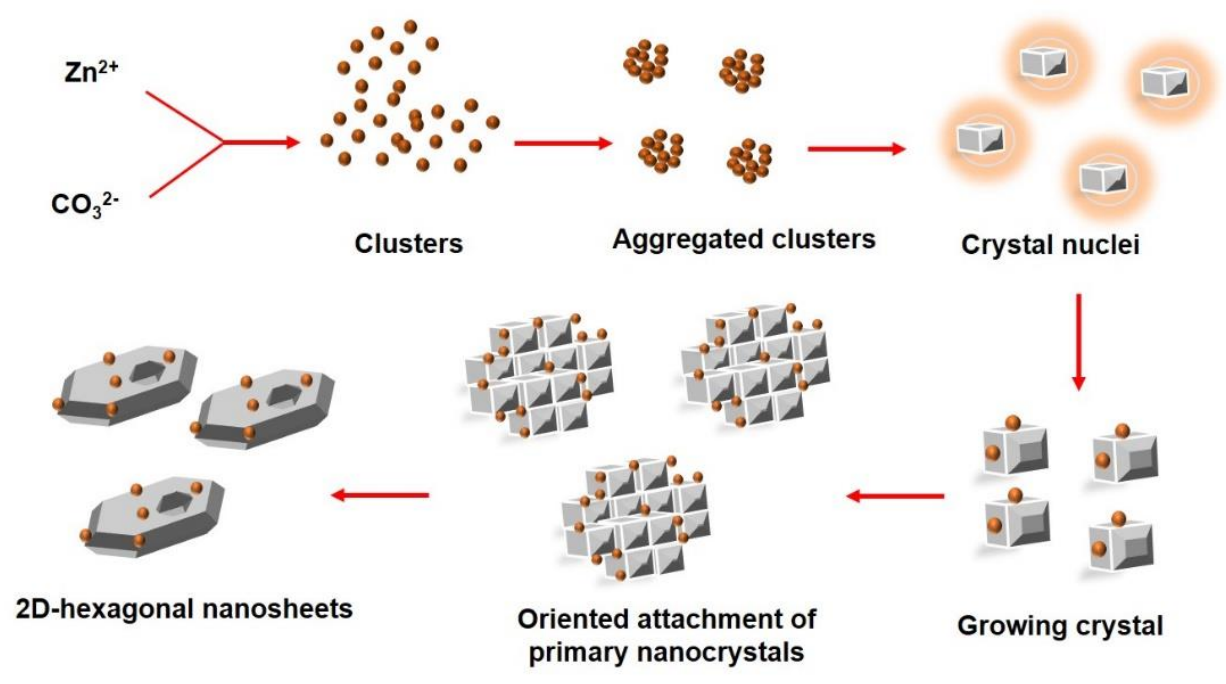

Figure 7: Scheme (not to scale) showing the different steps in the formation of $\mathrm{Zn}_{5}\left(\mathrm{CO}_{3}\right)_{2}$. $(\mathrm{OH})_{6}$ architectured structures from clusters formation to $2 \mathrm{D}$ orientation attachment into hexagonal nanosheets, in pure $\mathrm{H}_{2} \mathrm{O}$ or ethanol/ $\mathrm{H}_{2} \mathrm{O}(1 / 4 \mathrm{v} / \mathrm{v})$. 
PAC is a water-soluble polymer that does not form micelles in solution and it is an anionic polymer $(\mathrm{pH}=5-9)$ in aqueous solution. PAC has carboxyl groups $\left(-\mathrm{COO}^{-}\right)$and can selectively and strongly bind to the active sites of the $\mathrm{ZnCO}_{3}$ hydroxide nanosheets, reducing the number of growth sites and inhibits nucleation and growth on the primary nanosheets [53]. In presence of PAC, the primary nanosheets would not grow out but they tend to stick together in 3D layer-by-layer assembly (Figure 8). PAC molecules (anionic) seem to strongly adsorb on the upper and lower surface of the primary nanosheets, results in the formation of nanosheets with a planar surface (ZC-PAC).

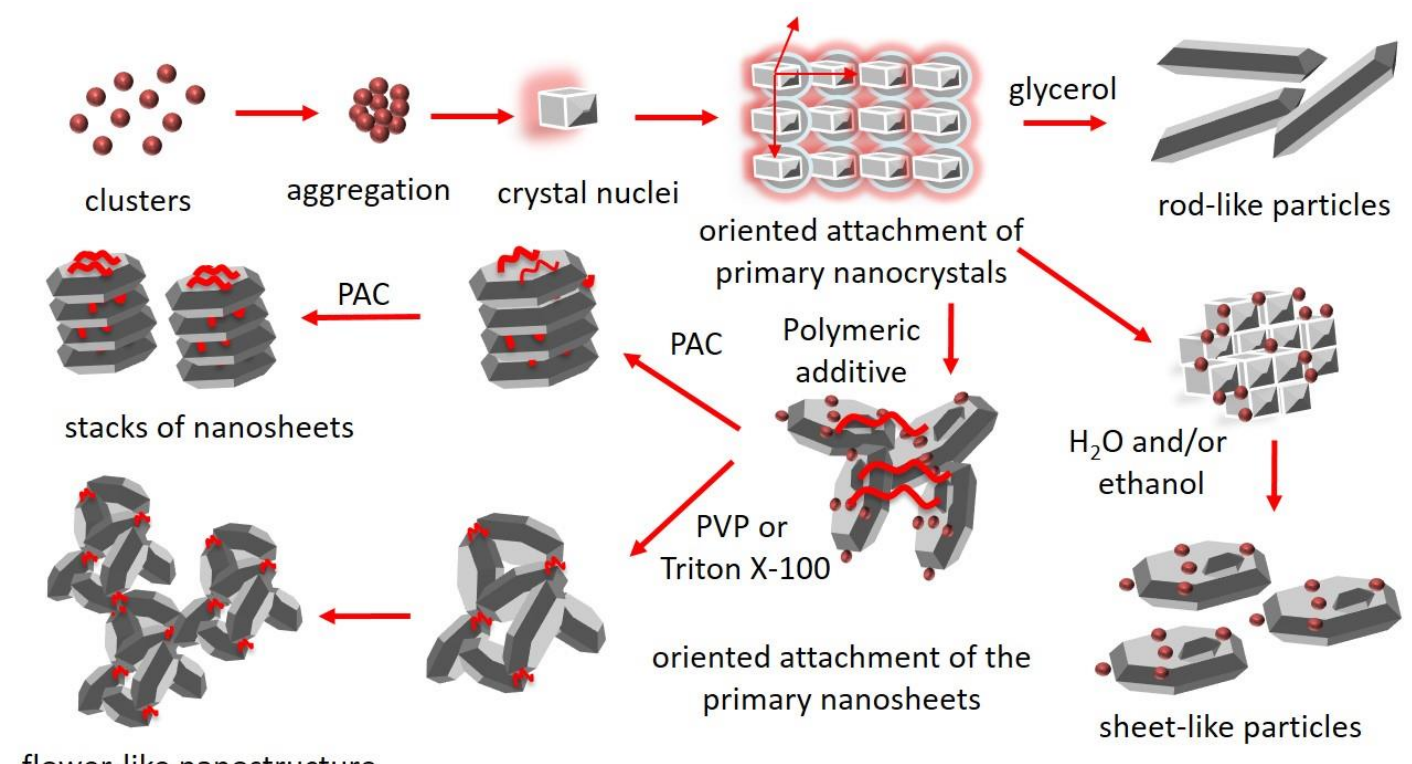

Figure 8: Scheme (not to scale) showing the different steps in the formation of $\mathrm{Zn}_{5}\left(\mathrm{CO}_{3}\right)_{2} .(\mathrm{OH})_{6}$ from cluster formation to 3D orientation attachment into 1-3D nanostructures.

The oriented attachment of $\mathrm{ZnCO}_{3}$ particles in presence of PVP (polymeric) and Triton X-100 finally results in cross-linked porous structures of pyramidal-shaped nanosheets. PVP is a cationic polymer that does not form micelles in solution but it is partially protonated (so cationic) at a $\mathrm{pH}$ of 5 and lower and essentially neutral above a pH of 8 (PVP, $\mathrm{pKa}=5)$.[56] Unlike PVP, Triton $\mathrm{X}-100$ is non-ionic surfactant which can form micelles in solution. Selvam et al.[16] reported that Triton X-100 exists as single (nonionic) molecules at low concentration $\left(2.1 \times 10^{-4} \mathrm{~mol} \cdot \mathrm{L}^{-1}\right)$, and as rod-like micelles at higher concentrations $\left(1.3 \times 10^{-3} \mathrm{~mol} \cdot \mathrm{L}^{-1}\right)$. Recent investigations revealed that Triton $\mathrm{X}-100$ could be easily removed by washing the $\mathrm{ZnCO}_{3}$ precipitate with water and 
ethanol at room temperature.[57] However, PVP (cationic) and Triton X-100 (non-ionic) weakly interact with the $\mathrm{ZnCO}_{3}$ hydroxide skeleton. PVP and Triton X-100 seems to be less selectively bind to the edges of the primary nanosheets, results in edge-to-edge attachment, and formation of 3D structures.

\subsection{Thermal transformation mechanism of $\mathrm{ZnCO}_{3}$ hydroxides into $\mathrm{ZnO}$ nanostructures}

The thermal decomposition reaction is a complicated process. Parameters such as the nature of the materials, gases in the atmosphere, heating rate, reactants mass, and type of crucible have significant effects on crystal structure, crystallite size, particle size and shape of annealed materials. In our experiments, a temperature of $600^{\circ} \mathrm{C}$ was selected to remove organic compounds and obtain pure structured $\mathrm{ZnO}$ particles. The mechanism of the thermal decomposition of the $\mathrm{Zn}_{5}\left(\mathrm{CO}_{3}\right)_{2}(\mathrm{OH})_{6}$ into $\mathrm{ZnO}$ particles can be explained by thermal shrinking core model in the literature[58],[38]. The de-carboxylation and de-hydroxylation of $\mathrm{Zn}_{5}\left(\mathrm{CO}_{3}\right)_{2}(\mathrm{OH})_{6}$ particles occur simultaneously. However, these processes are separated in the other phases, i.e. $\mathrm{ZnCO}_{3}, \mathrm{ZnO}$, and $\cdot \mathrm{H}_{2} \mathrm{O}$ [59]. Upon annealing, the $\mathrm{H}_{2} \mathrm{O}$ and $\mathrm{CO}_{2}$ by-products are eliminated and the micro-sized aggregates of $\mathrm{ZnCO}_{3}$ hydroxide particles break-up into smaller $\mathrm{ZnO}$ particles, except for $\mathrm{ZC}$-Trit, where the particle size and morphology (Figure 4) did not show significant changes upon annealing (see Figure 5 and 6).

The variation in shape, size and size distribution of the produced $\mathrm{ZnO}$ particles is attributed to the nature and volume of gases escaping during the annealing process. The thermal decomposition of growth-control additives and the dehydration and decarbonation of the $\mathrm{ZnCO}_{3}$ hydroxide aggregates induce the breaking-down of the particles and the formation of smaller $\mathrm{ZnO}$ particles. The nonionic surfactant Triton X-100 plays a key role in the thermal formation of the $3 \mathrm{D} \mathrm{ZnO}$ nanostructures. As indicated by the TGA results, ZC-Trit and ZC-PVP particles have the highest thermal stability (Figure 3). Only for $\mathrm{ZC}-\mathrm{H}_{2} \mathrm{O}$ and ZC-Trit, the particle size and morphology (Figure 4) did not change markedly upon annealing (by comparing $\mathrm{ZC}-\mathrm{H}_{2} \mathrm{O}$ and $\mathrm{ZC}-$ Trit in Figure 4 with Z- $\mathrm{H}_{2} \mathrm{O}$ and Z-Trit in Figure 5), which is attributed to the efficient removal of Triton X-100 upon washing with water prior to thermal decarbonation. In a second step, the produced $\mathrm{ZnO}$ particles get converted to a more uniform intermediate size (Ostwald ripening), as indicated by the narrow particle size distribution of Z-PVP. The particles undergo significant transformations are also illustrated by the larger crystallite size after dehydration and decarbonation compared to before (except for Z-Eth). This hypothesis greed with the XRD, TGA and SEM, however, the 
detailed mechanism for the formation of porous nanostructures and nonporous nanoparticles is still under investigation by our group. A proposed pathway of thermal decomposition that explain morphological changes and the formation of porous nanostructures and nonporous nanoparticles made of $\mathrm{ZnO}$ is shown in Figure 9.

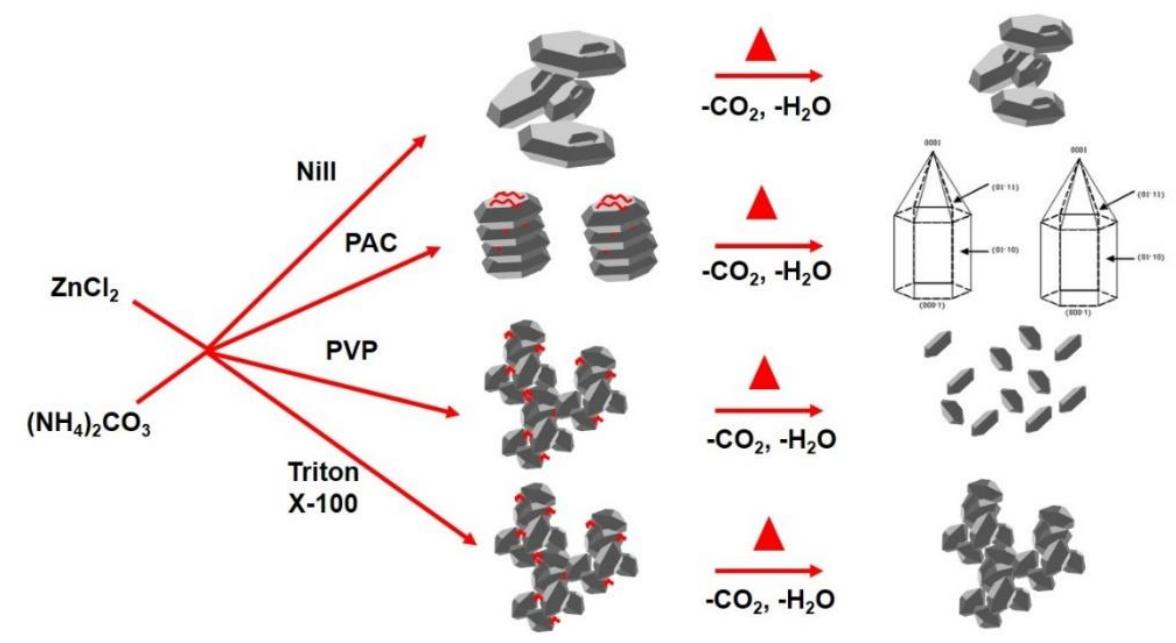

Figure 9. The proposed pathway of thermal decomposition that explains the morphological changes and the formation of porous microsized particles and nonporous $\mathrm{ZnO}$ nanoparticles

\subsection{Photocatalytic oxidation of methanol}

Illumination of aqueous $\mathrm{ZnO}$ particle suspensions containing methanol and oxygen leads to the oxidation of methanol and formation of formaldehyde ( $\mathrm{HCHO}$ ). The HCHO concentration increases monotonously and the reaction rate decelerates slightly with illumination time (Figure 10a). UV-vis spectroscopy is widely used to investigate the optical bandgap energy. However, it is well known that the direct observation of the bandgap variation as a function of the particle size and shape and surface defects from UV spectra is relatively rare. For all prepared $\mathrm{ZnO}$ photocatalysts, the bandgap energy is within the range from 3.23 to $3.25 \mathrm{eV}$ (Figure 10b). The light intensity is also very important factor affecting the photocatalytic activity. The light intensity directly influences the photocatalytic reaction rate and the utilization ratio of energy. Therefore its rational selection has vital significance for saving energy [60]. The photonic efficiency $(\xi)$ was derived for the prepared $\mathrm{ZnO}$ photocatalysts and is listed in Table 3. The photonic efficiency of the $\mathrm{ZnO}$ NPs is in the range of 3-8\% and varies in the following order: Z-Eth $<$ Z-Gly $<$ Z-PAC $\approx$ Z-PVP $<$ Z-Trit. The highly porous structure Z-Trit is beneficial for the photocatalytic oxidation methanol. The photonic efficiency obtained for the porous Z-Trit particles $(7.5 \%)$ is higher than 
for all other prepared nonporous $\mathrm{ZnO}$ NPs (3.5-6.5\%) and two times higher than the efficiency of the nonporous Z-Eth particles (3.5\%) [61]. The higher conversion efficiency of the micro-sized ZTrit particles $(5 \pm 0.5 \mu \mathrm{m})$ is attributed to the porous nanostructure and higher surface area compared to the nonporous $\mathrm{ZnO}$ NPs $(\leq 450 \mathrm{~nm})$. According to the literature, the porous Z-trit network can act as an antenna system (Figure 11), which transfers the initially generated electrons from the location of light absorption to a suitable interface [62]. The Z-Trit particles follow this model. They are considered to be composed of partially sintered crystallites that are interconnected by grain boundaries. On the surface of the grains, adsorbed methanol molecules extract electrons from the conduction band and trap the electrons at the surface in the form of ions [63]. The excited $\mathrm{ZnO}$ crystallites can transfer the absorbed energy through the porous $\mathrm{ZnO}$ network to other ground-state $\mathrm{ZnO}$ crystallites. Under the UV irradiation, electrons are photoexcited to the conduction band (CB) from the valence band (VB) and holes are left in the valence band. Electron-hole pairs can quickly transfer to the surface of $\mathrm{ZnO}$ particles and react with water and oxygen adsorbed on the surface of catalysts to generate highly reactive oxygen species such as hydroxyl radical (-OH') [60]. The probability of the hole trapping at the surface forming an adsorbed hydroxyl radical $\left(-\mathrm{OH}^{\prime}\right)$ that is subsequently transferred to an adsorbed $\mathrm{CH}_{3} \mathrm{OH}$ molecule is considered to be high. Consequently, the probability of electron transfer through the structure until arriving at a suitable trap site increases as the $\mathrm{CH}_{3} \mathrm{OH}$ diffusion through the pores of the nanostructures increasing [64]. Once one of the charge carriers has been involved in a redox reaction with the adsorbate, it is trapped and the other charge carrier can continue its journey through the particle network until reacting itself. Trap sites, for example, can be formed through the adsorption of electron acceptors and/or donors on one of the particles belonging to the aggregate. The good electron mobility within the network, could result from a decrease of the defect density by a reduction of the grain boundaries, resulting in an improved photocatalytic activity of the overall system, through a cooperative effect within the network [64]. Furthermore the holes in this porous structure provide ideal channels for an efficient diffusion of the methanol molecules to contact the different interplanar surfaces of the $\mathrm{ZnO}$ nanosheets, and also greatly increases the efficiency of UV irradiation [21]. 

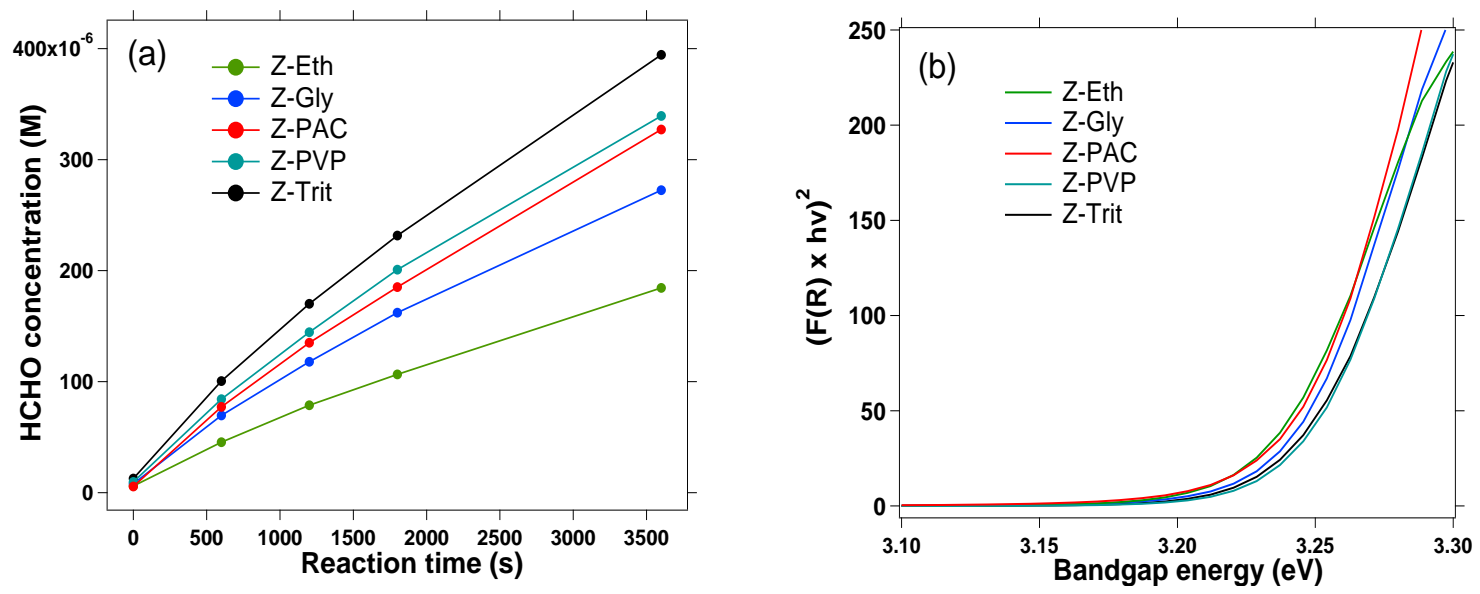

Figure 10: Determination of photocatalytic activity of the prepared $\mathrm{ZnO}$ photocatalysts: (a) effect of illumination time on the concentration of $\mathrm{HCHO}$ formed by photocatalytic oxidation of $\mathrm{CH}_{3} \mathrm{OH}(30 \mathrm{mM})$ in $\mathrm{O}_{2}$-saturated aqueous suspension of the prepared $\mathrm{ZnO}$ particles; and (b) bandgap energy.

For nonporous particles, the decrease in particle size usually leads to the reduction of volume recombination, because the migration time of photogenerated charge carriers to the surface is proportional to the square of the particle size [65]. The overall number of surface active sites increases with decreasing the particle sizes, which results in a higher interfacial charge transfer rate [61]. Among the nonporous ZnO NPs, Z-PVP (particle size $80 \pm 20 \mathrm{~nm}$ ) is the most efficient photocatalyst for methanol oxidation (Figure 9a). For the nonporous Z-Eth and Z-PAC particles, having similar particle sizes, the javelin Z-PAC particles have higher surface area and photocatalytic activity than the rhombohedral Z-Eth particles, for which a comparatively low reaction rate was obtained. 


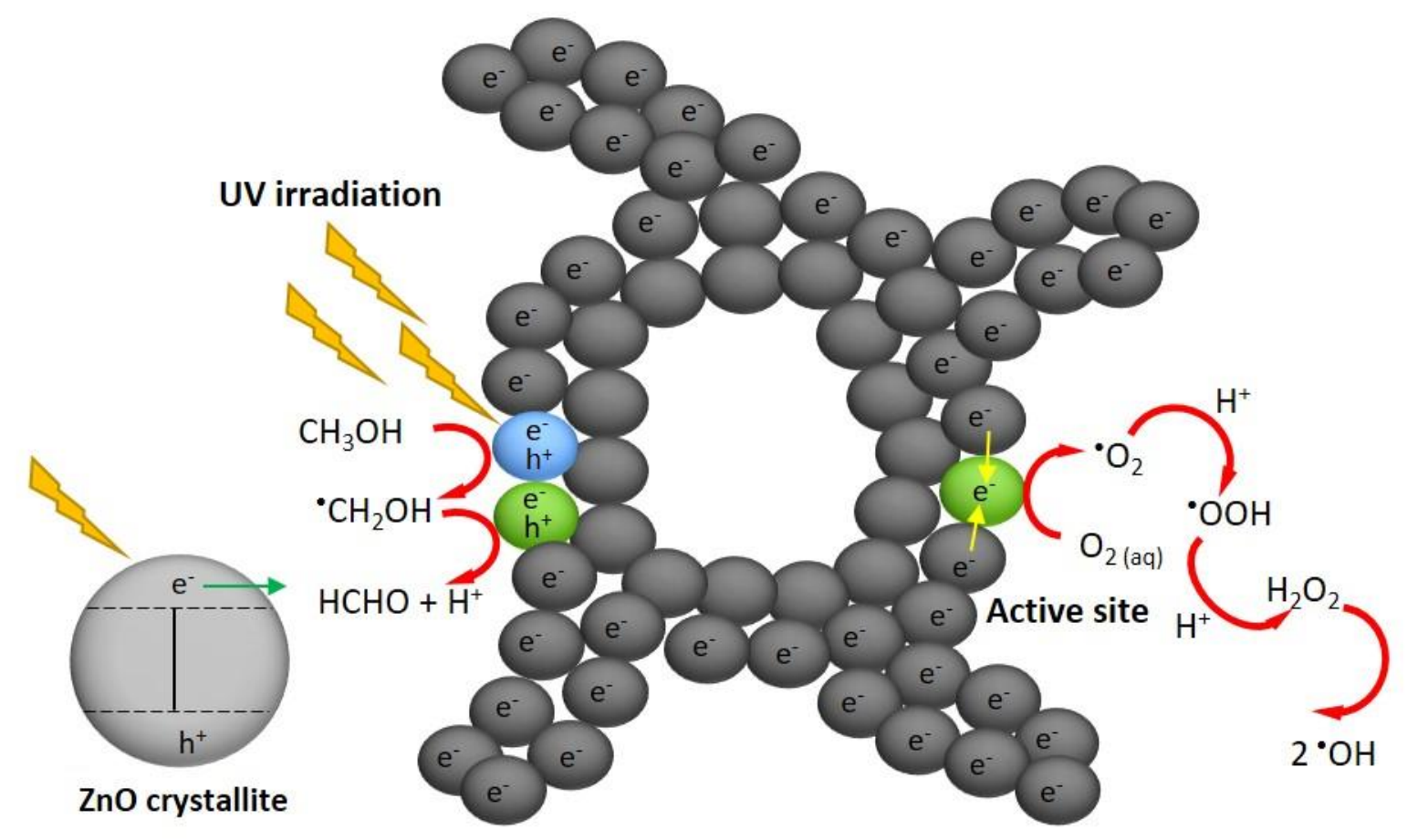

Figure 11: The photocatalytic pathway in porous $\mathrm{ZnO}$ nanostructure (Z-Trit) in an aqueous methanol solutions.

\section{CONCLUSION}

Enhancing photocatalytic activity based on shape and size control is a complex process, requiring a fundamental comprehension of the interactions of reagents and photocatalysts. In this work, we successfully synthesized $\mathrm{ZnCO}_{3}$ hydroxide nanostructures of individual nanoparticles, i.e. rodlike, sheet-like, and flower-like particles. The $\mathrm{ZnCO}_{3}$ hydroxides were prepared through directwet carbonation of an aqueous solution of $\mathrm{ZnCl}_{2}$ with $\left(\mathrm{NH}_{4}\right)_{2} \mathrm{CO}_{3}$ in presence of growth controlled additives (ethanol, glycerol, PAC, PVP and Triton X-100). Porous microsized $\mathrm{ZnO}$ particles $(5 \pm 0.5 \mu \mathrm{m})$ and nonporous particles $(\leq 450 \mathrm{~nm})$, having a hexagonal wurtzite crystal structure, were prepared by annealing the $\mathrm{ZnCO}_{3}$ hydroxides at $600{ }^{\circ} \mathrm{C}$ for $24 \mathrm{~h}$. As the crystal structure and crystallite sizes were nearly the same $(64 \pm 3 \mathrm{~nm})$, notwithstanding very different particle morphologies, the effect of particle shape and size on the photocatalytic activity of $\mathrm{ZnO}$ was investigated. Interestingly, it was found that the photonic efficiency of the microsized porous particles towards the photooxidation of methanol is about two times higher than for the nonporous rhombohedral $\mathrm{ZnO}$ particles (about $200 \mathrm{~nm}$ ). On the other hand, the javelin-shaped $\mathrm{ZnO}$ particles 
are higher in photocatalytic activity than rhombohedral $\mathrm{ZnO}$ particles of similar size (about 200 $\mathrm{nm}$ ), which is attributed to an effect of the (nonporous) particle shape. The porous Z-trit network can act as an antenna system, which transfers the initially generated electrons from the location of light absorption to a suitable interface. This mechanism is operative when there is a substantial Fermi-level gradient between the light-absorbing crystallite and the catalytic crystallite. Further work is required to get a deeper insight into the real inter-particle charge-transfer mechanism. In situ addition of noble-metal salts during the carbonation process may produce a new composite nanostructured based $\mathrm{ZnCO}_{3}$. The thermal decomposition of these composites will allow to introduce the noble-metals inside the produced $\mathrm{ZnO}$ matrix. This strategy will further enhance the photocatalytic activity of produced $\mathrm{ZnO}$.

\section{ACKNOWLEDGMENTS}

This work was performed during research stay of Dr. Ahmed Barhoum at Institute of Technical Chemistry, Leibniz Universität Hannover and Institut Européen des Membranes, Université Montpellier, France. The authors would like to thank the FWO-Research Foundation Flanders (grant no V450315N and V423116N), Strategic Initiative Materials in Flanders (SBO- project no. 130529 - Insitu), European Regional Development Fund (Nanokomp as part of the program "Europa fördert Niedersachsen"; grant no. WA3-80125215) and ERLUS AG for financial support. Notes that the authors declare no competing financial interest.

\section{References}

1. Zhang L, Wang W, Zhou L, Xu H (2007) Bi2WO6 nano- and microstructures: shape control and associated visible-light-driven photocatalytic activities. Small 3:1618-25. doi: 10.1002/smll.200700043

2. Lee HU, Lee SC, Lee Y-C, et al (2014) Innovative three-dimensional (3D) eco-TiO photocatalysts for practical environmental and bio-medical applications. Sci Rep 4:6740. doi: 10.1038/srep06740

3. McLaren A, Valdes-Solis T, Li G, Tsang SC (2009) Shape and size effects of ZnO nanocrystals on photocatalytic activity. J Am Chem Soc 131:12540-1. doi: 10.1021/ja9052703

4. Jang ES, Won J-H, Hwang S-J, Choy J-H (2006) Fine Tuning of the Face Orientation of ZnO Crystals to Optimize Their Photocatalytic Activity. Adv Mater 18:3309-3312. doi: 10.1002/adma.200601455 
5. Zhao T, Zhao Y, Jiang L (2013) Nano-/microstructure improved photocatalytic activities of semiconductors. Philos Trans A Math Phys Eng Sci 371:20120303. doi: 10.1098/rsta.2012.0303

6. Becker J, Raghupathi KR, St. Pierre J, et al (2011) Tuning of the Crystallite and Particle Sizes of ZnO Nanocrystalline Materials in Solvothermal Synthesis and Their Photocatalytic Activity for Dye Degradation. J Phys Chem C 115:13844-13850. doi: 10.1021/jp2038653

7. Dodd AC, McKinley AJ, Saunders M, Tsuzuki T (2006) Effect of Particle Size on the Photocatalytic Activity of Nanoparticulate Zinc Oxide. J Nanoparticle Res 8:43-51. doi: 10.1007/s11051-005-5131-z

8. Manikandan E, Moodley MK, Sinha Ray S, et al (2010) Zinc oxide epitaxial thin film deposited over carbon on various substrate by pulsed laser deposition technique. J Nanosci Nanotechnol 10:5602-11.

9. Park KT, Xia F, Kim SW, et al (2013) Facile Synthesis of Ultrathin ZnO Nanotubes with WellOrganized Hexagonal Nanowalls and Sealed Layouts: Applications for Lithium Ion Battery Anodes. J Phys Chem C 117:1037-1043. doi: 10.1021/jp310428r

10. Wang Y, Li X, Wang N, et al (2008) Controllable synthesis of $\mathrm{ZnO}$ nanoflowers and their morphology-dependent photocatalytic activities. Sep Purif Technol 62:727-732. doi: 10.1016/j.seppur.2008.03.035

11. Lao JY, Huang JY, Wang DZ, Ren ZF (2003) ZnO Nanobridges and Nanonails. Nano Lett 3:235238. doi: $10.1021 / \mathrm{nl} 1025884 \mathrm{u}$

12. Zhao F, Zheng J-G, Yang X, et al (2010) Complex ZnO nanotree arrays with tunable top, stem and branch structures. Nanoscale 2:1674. doi: 10.1039/c0nr00076k

13. Kołodziejczak-Radzimska A, Jesionowski T (2014) Zinc Oxide-From Synthesis to Application: A Review. Materials (Basel) 7:2833-2881. doi: 10.3390/ma7042833

14. Mahmud S, Abdullah M, Putrus G, et al (2006) Nanostructure of ZnO fabricated via French process and its correlation to electrical properties of semiconducting varistors. Synth. React. Inorganic, Met. Nano-Metal Chem.

15. Moezzi A, McDonagh AM, Cortie MB (2012) Zinc oxide particles: Synthesis, properties and applications. Chem Eng J 185-186:1-22. doi: 10.1016/j.cej.2012.01.076

16. Clament Sagaya Selvam N, Vijaya JJ, Kennedy LJ (2012) Effects of Morphology and Zr Doping on Structural, Optical, and Photocatalytic Properties of ZnO Nanostructures. Ind Eng Chem Res 51:16333-16345. doi: 10.1021/ie3016945

17. Cho S, Jung S-H, Lee K-H (2008) Morphology-Controlled Growth of ZnO Nanostructures Using Microwave Irradiation: from Basic to Complex Structures. J Phys Chem C 112:12769-12776. doi: 10.1021/jp803783s 
18. Wang J, Lee Y-J, Hsu JWP (2014) One-Step Synthesis of ZnO Nanocrystals in n -Butanol with Bandgap Control: Applications in Hybrid and Organic Photovoltaic Devices. J Phys Chem C 118:18417-18423. doi: 10.1021/jp505058u

19. Zhang X, Qin J, Xue Y, et al (2014) Effect of aspect ratio and surface defects on the photocatalytic activity of ZnO nanorods. Sci Rep 4:4596. doi: 10.1038/srep04596

20. McCune M, Zhang W, Deng Y (2012) High efficiency dye-sensitized solar cells based on threedimensional multilayered $\mathrm{ZnO}$ nanowire arrays with “caterpillar-like" structure. Nano Lett 12:3656-62. doi: 10.1021/nl301407b

21. Duan X, Wang G, Wang H, et al (2010) Orientable pore-size-distribution of ZnO nanostructures and their superior photocatalytic activity. CrystEngComm 12:2821. doi: 10.1039/b922679f

22. Liu Y, Shi J, Peng Q, Li Y (2012) Self-assembly of ZnO nanocrystals into nanoporous pyramids: high selective adsorption and photocatalytic activity. J Mater Chem 22:6539. doi: $10.1039 / \mathrm{c} 2 \mathrm{jm} 16729 \mathrm{~h}$

23. Xie H, Li Y, Jin S, et al (2010) Facile Fabrication of 3D-Ordered Macroporous Nanocrystalline Iron Oxide Films with Highly Efficient Visible Light Induced Photocatalytic Activity. J Phys Chem C 114:9706-9712. doi: 10.1021/jp102525y

24. Barhoum A, Ibrahim HM, Hassanein TF, et al (2014) Preparation and characterization of ultrahydrophobic calcium carbonate nanoparticles. IOP Conf Ser Mater Sci Eng 64:12037. doi: 10.1088/1757-899X/64/1/012037

25. Do T-DN and T-O (2011) Nanocrystal. doi: 10.5772/703

26. LaGrow AP, Ingham B, Toney MF, Tilley RD (2013) Effect of Surfactant Concentration and Aggregation on the Growth Kinetics of Nickel Nanoparticles. J Phys Chem C 117:16709-16718. doi: $10.1021 / j p 405314 \mathrm{~g}$

27. El-Sheikh SM, Barhoum A, El-Sherbiny S, et al (2014) Preparation of superhydrophobic nanocalcite crystals using Box-Behnken design. Arab J Chem. doi: 10.1016/j.arabjc.2014.11.003

28. Qi X, Balankura T, Zhou Y, Fichthorn KA (2015) How Structure-Directing Agents Control Nanocrystal Shape: Polyvinylpyrrolidone-Mediated Growth of Ag Nanocubes. Nano Lett 15:7711-7. doi: 10.1021/acs.nanolett.5b04204

29. Bullen CR, Mulvaney P (2004) Nucleation and Growth Kinetics of CdSe Nanocrystals in Octadecene. Nano Lett 4:2303-2307. doi: 10.1021/n10496724

30. Barhoum A, Rehan MF, Rahier H, et al (2016) Seed-mediated hot injection synthesis of tiny Ag nanocrystals on nanoscale solid supports and reaction mechanism. ACS Appl Mater Interfaces. doi: 10.1021/acsami.5b10405

31. van Embden J, Mulvaney P (2005) Nucleation and growth of CdSe nanocrystals in a binary ligand 
system. Langmuir 21:10226-33. doi: 10.1021/la0510811

32. Potti PR, Srivastava VC (2012) Comparative Studies on Structural, Optical, and Textural Properties of Combustion Derived ZnO Prepared Using Various Fuels and Their Photocatalytic Activity. Ind Eng Chem Res 51:7948-7956. doi: 10.1021/ie300478y

33. Holzwarth U, Gibson N (2011) The Scherrer equation versus the "Debye-Scherrer equation." doi: 10.1038/nnano.2011.145

34. Christy AA, Kvalheim OM, Velapoldi RA (1995) Quantitative analysis in diffuse reflectance spectrometry: A modified Kubelka-Munk equation. Vib Spectrosc 9:19-27. doi: 10.1016/09242031(94)00065-O

35. NASH T (1953) The colorimetric estimation of formaldehyde by means of the Hantzsch reaction. Biochem J 55:416-21.

36. Fateh R, Dillert R, Bahnemann D (2014) Self-cleaning properties, mechanical stability, and adhesion strength of transparent photocatalytic $\mathrm{TiO}(2)-\mathrm{ZnO}$ coatings on polycarbonate. ACS Appl Mater Interfaces 6:2270-8. doi: 10.1021/am4051876

37. Moghaddam J, Ghaffari SB, Sarraf-Mamoory R, Mollaesmail S (2014) The Study on the Crystallization Conditions of $\mathrm{Zn} 5(\mathrm{OH}) 6(\mathrm{CO} 3) 2$ and its Effect on Precipitation of $\mathrm{ZnO}$ Nanoparticles from Purified Zinc Ammoniacal Solution. Synth React Inorganic, Met Nano-Metal Chem 44:895-901. doi: 10.1080/15533174.2012.740738

38. Kanari N, Mishra D, Gaballah I, Dupré B (2004) Thermal decomposition of zinc carbonate hydroxide. Thermochim Acta 410:93-100. doi: 10.1016/S0040-6031(03)00396-4

39. El-Sheikh SM, El-Sherbiny S, Barhoum A, Deng Y (2013) Effects of cationic surfactant during the precipitation of calcium carbonate nano-particles on their size, morphology, and other characteristics. Colloids Surfaces A Physicochem Eng Asp 422:44-49. doi:

10.1016/j.colsurfa.2013.01.020

40. Barhoum A, Van Lokeren L, Rahier H, et al (2015) Roles of in situ surface modification in controlling the growth and crystallization of $\mathrm{CaCO} 3$ nanoparticles, and their dispersion in polymeric materials. J Mater Sci 50:7908-7918. doi: 10.1007/s10853-015-9327-z

41. Barhoum A, Rahier H, Abou-Zaied RE, et al (2014) Effect of cationic and anionic surfactants on the application of calcium carbonate nanoparticles in paper coating. ACS Appl Mater Interfaces 6:2734-44. doi: 10.1021/am405278j

42. Barhoum A, Van Assche G, Makhlouf ASH, et al (2015) A Green, Simple Chemical Route for the Synthesis of Pure Nanocalcite Crystals. Cryst Growth Des 15:573-580. doi: 10.1021/cg501121t

43. Kumar SG, Rao KSRK (2015) Zinc oxide based photocatalysis: tailoring surface-bulk structure and related interfacial charge carrier dynamics for better environmental applications. RSC Adv 
5:3306-3351. doi: 10.1039/C4RA13299H

44. Gebauer D, Völkel A, Cölfen H (2008) Stable prenucleation calcium carbonate clusters. Science 322:1819-22. doi: 10.1126/science.1164271

45. Song R-Q, Cölfen H (2011) Additive controlled crystallization. CrystEngComm 13:1249. doi: 10.1039/c0ce00419g

46. Peng Y, Wang F, Wang Z, et al (2015) Two-step nucleation mechanism in solid-solid phase transitions. Nat Mater 14:101-8. doi: 10.1038/nmat4083

47. Kawasaki T, Tanaka H (2010) Formation of a crystal nucleus from liquid. Proc Natl Acad Sci U S A 107:14036-41. doi: 10.1073/pnas.1001040107

48. Sun Y, Wang L, Yu X, Chen K (2012) Facile synthesis of flower-like 3D ZnO superstructures via solution route. CrystEngComm 14:3199. doi: 10.1039/c2ce06335b

49. Panmand RP, Sethi YA, Kadam SR, et al (2015) Self-assembled hierarchical nanostructures of Bi 2 WO 6 for hydrogen production and dye degradation under solar light. CrystEngComm 17:107115. doi: 10.1039/C4CE01968G

50. Shi W, Huo L, Wang H, et al (2006) Hydrothermal growth and gas sensing property of flowershaped SnS 2 nanostructures. Nanotechnology 17:2918-2924. doi: 10.1088/0957-4484/17/12/016

51. Thanh NTK, Maclean N, Mahiddine S (2014) Mechanisms of nucleation and growth of nanoparticles in solution. Chem Rev 114:7610-30. doi: 10.1021/cr400544s

52. Wang F, Wang X (2014) Mechanisms in the solution growth of free-standing two-dimensional inorganic nanomaterials. Nanoscale 6:6398-414. doi: 10.1039/c4nr00973h

53. Jradi K, Maury C, Daneault C (2015) Contribution of TEMPO-Oxidized Cellulose Gel in the Formation of Flower-Like Zinc Oxide Superstructures: Characterization of the TOCgel/ZnO Composite Films. Appl Sci 5:1164-1183. doi: 10.3390/app5041164

54. Hong L, Li Q, Lin H, Li Y (2009) Synthesis of flower-like silver nanoarchitectures at room temperature. Mater Res Bull 44:1201-1204. doi: 10.1016/j.materresbull.2009.01.017

55. Bhattacharyya L, Rohrer JS (2012) Applications of Ion Chromatography for Pharmaceutical and Biological Products. John Wiley \& Sons, Inc., Hoboken, NJ, USA

56. Vos JG, Forster RJ, Keyes TE (2003) Interfacial Supramolecular Assemblies. John Wiley \& Sons

57. Wang Y, Jiang Z-H, Yang F-J (2006) Preparation and photocatalytic activity of mesoporous TiO2 derived from hydrolysis condensation with TX-100 as template. Mater Sci Eng B 128:229-233. doi: 10.1016/j.mseb.2005.12.004

58. Moezzi A, Cortie M, Dowd A, McDonagh A (2014) On the formation of nanocrystalline active zinc oxide from zinc hydroxide carbonate. J Nanoparticle Res 16:2344. doi: 10.1007/s11051-0142344-z 
59. Dollimore D, France JA, Krupay BW, Whitehead R (1980) Kinetic aspects of the thermal decomposition of zinc carbonate. Thermochim Acta 36:343-349. doi: 10.1016/00406031(80)87029-8

60. Yang L, Liu Z (2007) Study on light intensity in the process of photocatalytic degradation of indoor gaseous formaldehyde for saving energy. Energy Convers Manag 48:882-889. doi: 10.1016/j.enconman.2006.08.023

61. Wang C, Rabani J, Bahnemann DW, Dohrmann JK (2002) Photonic efficiency and quantum yield of formaldehyde formation from methanol in the presence of various $\mathrm{TiO} 2$ photocatalysts. $\mathrm{J}$ Photochem Photobiol A Chem 148:169-176. doi: 10.1016/S1010-6030(02)00087-4

62. Park Y, Kim W, Monllor-Satoca D, et al (2013) Role of Interparticle Charge Transfers in Agglomerated Photocatalyst Nanoparticles: Demonstration in Aqueous Suspension of DyeSensitized TiO2. J Phys Chem Lett 4:189-94. doi: 10.1021/jz301881d

63. Sun Y-F, Liu S-B, Meng F-L, et al (2012) Metal oxide nanostructures and their gas sensing properties: a review. Sensors (Basel) 12:2610-31. doi: 10.3390/s120302610

64. Schneider J, Matsuoka M, Takeuchi M, et al (2014) Understanding TiO 2 Photocatalysis: Mechanisms and Materials. Chem Rev 114:140919080959008. doi: 10.1021/cr5001892

65. Hagfeldt A, Graetzel M (1995) Light-Induced Redox Reactions in Nanocrystalline Systems. Chem Rev 95:49-68. doi: 10.1021/cr00033a003 